\title{
A versatilidade clínica do arco utilidade
}

Márcio Antonio de Figueiredo*, Claudia Tebet Peyres de Figueiredo**,

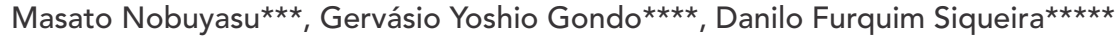

\begin{abstract}
Resumo
Introdução: dentro da ciência Bioprogressiva, o arco utilidade, juntamente com o quadrihélice, é o dispositivo mais conhecido e utilizado para o tratamento de inúmeras más oclusões. Com um desenho ao mesmo tempo simples e original, o arco utilidade tornou-se parte integrante do arsenal ortodôntico utilizado nos períodos das dentaduras mista e permanente. $\mathrm{O}$ nome do arco é uma referência à grande versatilidade que este dispositivo oferece, e devido aos vários efeitos que o mesmo pode promover durante o tratamento. Objetivo: este artigo destina-se a discutir a fabricação, a ativação e o uso clínico do arco utilidade de Ricketts no tratamento ortodôntico, além de descrever alguns dos princípios da técnica ortodôntica Bioprogressiva. Conclusão: pode-se concluir que o arco utilidade é um aparelho extremamente versátil, com inúmeras possibilidades clínicas, sendo capaz de intruir, extruir, avançar ou retrair os incisivos superiores e inferiores; manter, diminuir ou aumentar o espaço no arco inferior; além de ancorar os molares inferiores. Entretanto, uma das maiores vantagens de seu uso consiste na correção de más oclusões do tipo Classe II, com mordida profunda.
\end{abstract}

Palavras-chave: Bioprogressiva. Arco utilidade. Ortodontia.

\section{INTRODUÇÃO E REVISÃO DA LITERATURA}

$O$ arco utilidade é parte integrante da mecânica ortodôntica utilizada na "Ciência Bioprogressiva" de Ricketts. A palavra "Bioprogressiva" surgiu da união do prefixo "Bio" - abreviação de Biologia e se refere ao cuidado que a mecânica ortodôntica empregada tem com os processos biológicos envolvidos em um tratamento ortodôntico - e
"Progressiva", por refletir a seqüência lógica e progressiva utilizada na montagem dos aparelhos e conseqüente movimentação dos dentes.

Dentro desta ciência, o arco utilidade é, provavelmente, o dispositivo mais conhecido e utilizado $^{3}$, sendo confeccionado com o fio quadrado 0,016 " x 0,016" Elgiloy azul. Segundo Miksic, Slaj e Mestrovic ${ }^{17}$, este fio é composto por uma liga

* Especialista em Ortodontia/Ortopedia Facial pela UNICEB. Mestre pelo programa de pós-graduação em Odontologia - área de concentração em Ortodontia da Universidade Metodista de São Paulo - UMESP. Professor dos cursos de especialização em Ortodontia da UNOESTE Presidente Prudente e APCD de Ourinhos/SP.

** Especialista em Ortodontia/Ortopedia Facial pela UNOESTE. Clínica privada na cidade de Sorocaba/SP.

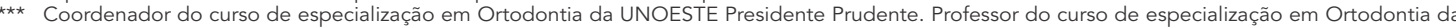
APCD de Ourinhos/SP.

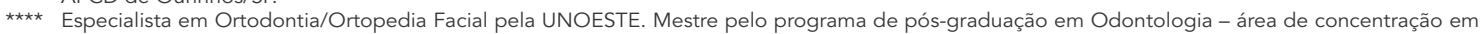

Ortodontia da Universidade Metodista de São Paulo - UMESP. Professor do curso de especialização em Ortodontia da ABO de Cuiabá/MT.
Doutor em Ortodontia pela FOB-USP. Professor do programa de pós-graduação em Odontologia (Mestrado) - área de concentração em Ortodontia da UMESP. 
de cromo-cobalto, o que facilita a confecção de dobras. Este arco, em conjunto com braquetes de canaleta 0,018 " x 0,030 "22 , começou a ser utilizado por Ricketts no tratamento ortodôntico/ortopédico facial em $1960^{24}$.

Com um desenho ao mesmo tempo simples e original (Fig. 1), o arco utilidade tornou-se parte integrante do arsenal ortodôntico utilizado nos períodos das dentaduras mista e permanente. $\mathrm{O}$ nome do arco é uma referência à grande versatilidade que este dispositivo oferece, e devido aos vários efeitos que o mesmo pode promover durante o tratamento.

De acordo com McNamara Jr. ${ }^{15,16}$, o arco utilidade é eficiente para intruir e, especialmente, efetivo para retruir ou avançar os incisivos superiores e inferiores. O mesmo autor salientou que uma das dificuldades para o tratamento das discrepâncias ântero-posteriores (particularmente a má oclusão do tipo Classe II de Angle) é a interferência vertical anterior. Nestes casos, o arco utilidade pode ser utilizado para intruir os incisivos, favorecendo a correção ortopédica, ou mesmo cirúrgica, da má oclusão. Segundo Sellke ${ }^{27}$ a correção do trespasse vertical antes do horizontal é um importante princípio do tratamento bioprogressivo. Este conceito está baseado na convicção de que uma mordida profunda pode "travar" e impedir o relacionamento normal entre a maxila e a mandíbula, durante o crescimento. Baseando-se nesta idéia, o arco utili-

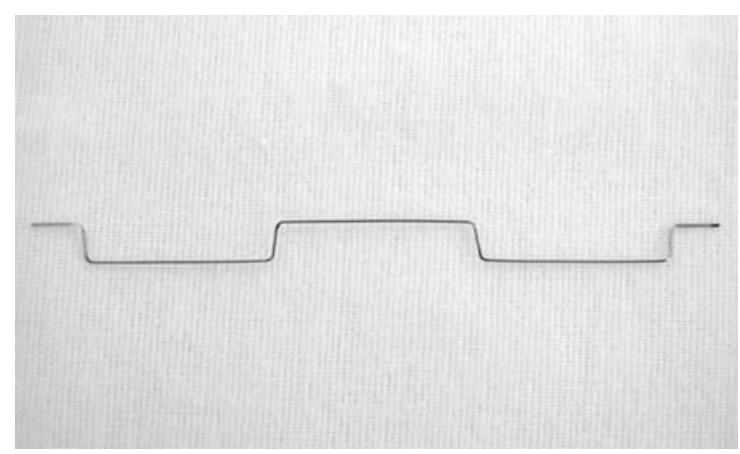

FIGURA 1 - Arco utilidade inferior confeccionado com fio Elgiloy azul 0,016" x 0,016 " da Rocky Mountain Orthodontics (RMO). dade, juntamente com o quadrihélice de Ricketts, pode ser utilizado no início do tratamento para "destravar" a oclusão, fornecendo condições morfológicas adequadas para que a mandíbula possa se desenvolver normalmente. Entretanto, algumas vezes, pode ser utilizado também nos estágios tardios do tratamento ${ }^{17}$.

No intuito de comunicar e compreender os procedimentos mecânicos que o tratamento bioprogressivo utiliza, Bench, Gugino e Hilgers ${ }^{1}$ publicaram, em 1977, dez princípios que regem este tratamento:

1) Utilização de um sistema de diagnóstico e tratamento por meio da aplicação dos objetivos visuais do tratamento (VTO) no plano de tratamento, na avaliação de ancoragem e no monitoramento dos resultados obtidos.

2) Controle do torque durante todo o tratamento. Utilizando-se, para tanto, o fio quadrado Elgiloy azul 0,016" x 0,016" do início (primeiro arco) ao final do tratamento.

3) Ancoragem cortical e muscular: o conceito de ancoragem cortical implica que, para ancorar um dente, suas raízes devem ser colocadas próximas ao osso cortical denso, com uma pressão duas vezes maior que a utilizada para movimentação, com o objetivo de diminuir ainda mais o já limitado fluxo sanguíneo presente no osso cortical, dificultando o movimento do dente. Ancoragem muscular é inerente aos pacientes do tipo braquifacial, portadores de uma musculatura mastigatória forte. Os músculos mastigatórios deste tipo facial dificultam o movimento dos dentes, por outro lado, pacientes do tipo facial dolicocefálico, que possuem uma musculatura mastigatória fraca, e que são menos capazes de suportar os efeitos extrusivos que o aparelho ortodôntico promove, apresentam mais facilmente uma abertura da mordida.

4) Movimento dos dentes em qualquer direção com a utilização de pressão adequada. A Bioprogressiva advoga que, com o uso dos valores corretos de força, qualquer dente pode ser movimenta- 
do em qualquer direção.

5) Alteração ortopédica: as alterações ortopédicas permanentes podem ser realizadas em crianças a partir dos três anos de idade, principalmente na maxila.

6) Correção do trespasse vertical antes do trespasse horizontal. Utilizando-se o arco utilidade pode-se tratar a mordida profunda antes do problema ântero-posterior. Este procedimento "destrava a oclusão" e permite que alterações ortopédicas na maxila e na mandíbula possam ser obtidas.

7) Tratamento com arco seccional: dividindo a má oclusão em partes (setores), um eficiente controle de ancoragem pode ser obtido, além de uma movimentação mais biológica. Em alguns casos não é instalado um arco contínuo próximo do final do tratamento e em outros pode não ser necessária a utilização de um arco ideal.

8) Conceito de sobretratamento do posicionamento individual de cada dente e da má oclusão.

9) Destravamento da oclusão em uma seqüência progressiva, para estabelecer ou restaurar uma função normal.

10) Eficiência no tratamento com resultados de qualidade, usando dispositivos pré-fabricados.

A técnica Bioprogressiva está baseada no fato de que o arco dentário é constituído por setores distintos $^{4}$, cada um dos quais possui características próprias com relação aos aspectos anatômicos, funcionais e estéticos (Fig. 2).

$\mathrm{O}$ setor dos incisivos constitui-se de dentes com raízes unirradiculares e de pequeno diâmetro, cujas bordas incisais tornam estes dentes aptos para realizar a função de corte dos alimentos, além de cumprirem um importante papel estético e fonético. Já os molares são multirradiculares, com a face oclusal destinada à trituração dos alimentos e com o diâmetro das raízes maior que o dos in$\operatorname{cisivos}^{10}$.

Quando a boca é dividida em setores e o arco utilidade é utilizado, pode-se controlar o posicionamento dos incisivos independentemente do setor lateral (caninos e pré-molares). Desta ma- neira, os quatros incisivos podem ser nivelados, mantidos em sua posição original, intruídos ou extruídos nas fases iniciais do tratamento. Além disso, é possível avançar ou retruir os incisivos sem afetar ou depender dos caninos ou dos prémolares. Os incisivos inferiores respondem idealmente quando são tratados como um segmento individual. Quando são amarrados aos dentes dos segmentos laterais (caninos e pré-molares), a resposta ideal está limitada por movimentos dos dentes destes segmentos.

Segundo Ricketts ${ }^{26}$, a força de erupção dos dentes é estimada em, aproximadamente, $0,2 \mathrm{~g}$ a $0,3 \mathrm{~g}$ por $\mathrm{mm}^{2}$, ou seja, $1 / 5$ da quantidade de força comumente empregada para movimentar um dente. Teoricamente, o dobro desta força $(0,4 \mathrm{~g}$ a $0,6 \mathrm{~g} / \mathrm{mm}^{2}$ ) impede a erupção dos dentes e o triplo desta força $\left(0,6 \mathrm{~g}\right.$ a $\left.0,9 \mathrm{~g} / \mathrm{mm}^{2}\right)$ intrui os dentes.

Otto, Anholm e Engel ${ }^{20}$ demonstraram ser possível, tanto em crianças como em adultos, o movimento de intrusão dos incisivos com a técnica Bioprogressiva, utilizando-se o arco utilidade. Os pesquisadores não encontraram nenhuma correlação entre idade, maturação esquelética, padrão facial e intrusão, sendo que, neste estudo, a maior intrusão obtida foi de $5,5 \mathrm{~mm}$ em uma paciente do gênero feminino com 32 anos de idade.

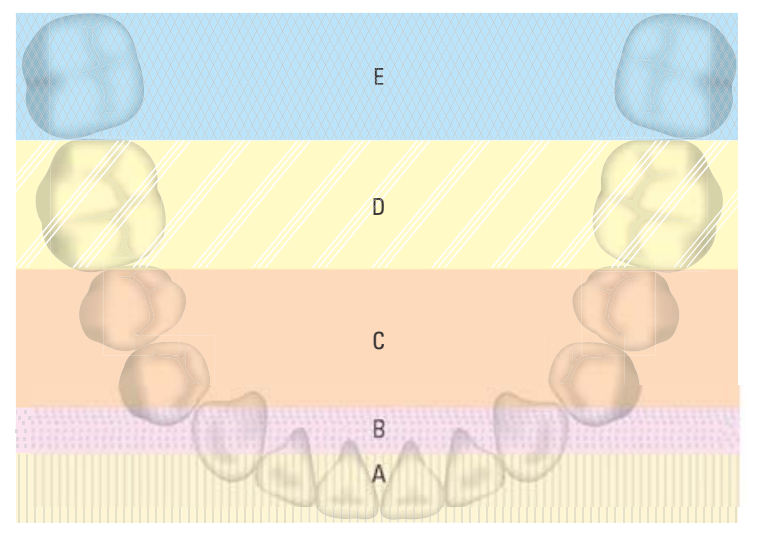

FIGURA 2 - Setores: A) incisivos, B) caninos, C) pré-molares, D) primeiros molares, E) segundos molares. 
$\mathrm{O}$ arco utilidade promove a intrusão dos incisivos por meio de um sistema de alavanca que produz uma pressão leve e contínua, em torno de 60 a 80 gramas para os quatro incisivos inferiores ${ }^{15,20}$. Visto que força por unidade de área é definida como pressão, a terapia Bioprogressiva advoga a utilização de 100 gramas de força por centímetro quadrado de raiz exposta ao movimento ${ }^{1}$, sendo que esta força pode ser multiplicada por dois quando a ancoragem cortical for o objetivo da mecânica, ou dividida por 2 quando os dentes serão movimentados pela cortical óssea. Isto significa que a força aplicada varia, dependendo do tamanho da raiz envolvida no movimento e da direção do movimento planejado. A análise da superfície radicular (Fig. 3) determina os va-

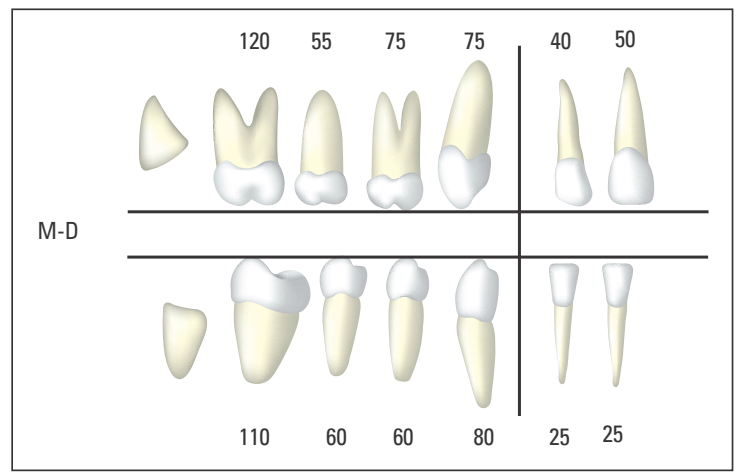

FIGURA 3 - Escala de avaliação da raiz no movimento ântero-posterior.

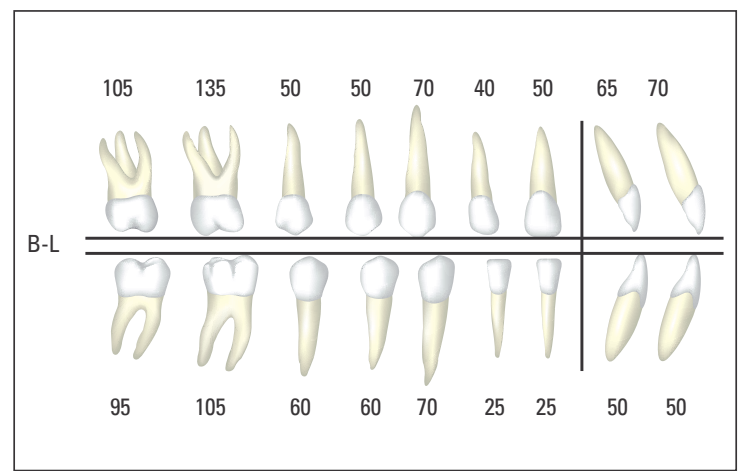

FIGURA 4 - Escala de avaliação da raiz no movimento transversal (direção lateral). lores utilizados para o movimento dos dentes no sentido ântero-posterior. Quando um dente do setor anterior é movimentado neste sentido, a superfície radicular que enfrentará o movimento é a vestibular ou a palatina. Entretanto, quando o mesmo movimento se realiza no segmento posterior, as superfícies radiculares envolvidas são a mesial e a distal.

Desta maneira, é sugerido por Bench, Gugino, Hilgers $^{5}$ e Ricketts ${ }^{24,25}$ que se aplique uma força de 40 gramas para o movimento de um incisivo lateral superior para vestibular e uma força de 120 gramas para o movimento de um primeiro molar superior para distal.

O mesmo tipo de análise é utilizado para determinar a força necessária para movimentar os dentes no sentido transversal (Fig. 4). Neste tipo de movimento, a região dos dentes anteriores analisada é a mesial ou a distal, e dos dentes posteriores é a vestibular ou palatina.

Por outro lado, para o movimento vertical dos dentes, que consiste na intrusão ou extrusão, analisa-se a área da maior secção transversal da superfície radicular (Fig. 5). Desta maneira pode-se verificar que são necessários 80 gramas de força para intruir um primeiro molar superior, devido ao seu maior diâmetro transversal apresentar $0,80 \mathrm{~cm}^{2}$, e os mesmos 80 gramas para intruir os quatros incisivos inferiores.

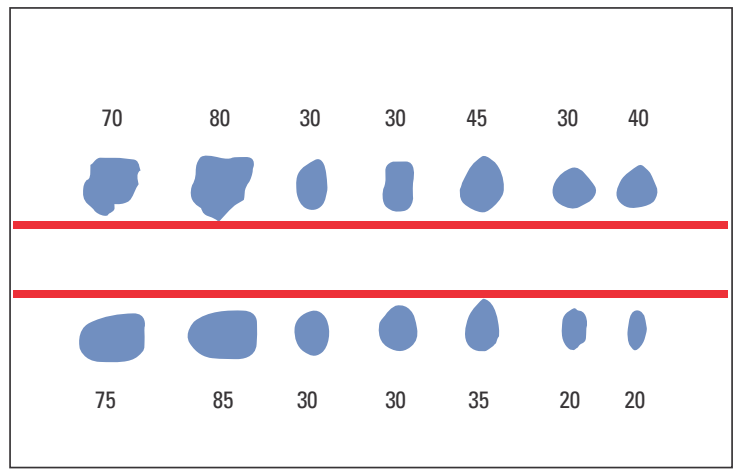

FIGURA 5 - Escala de avaliação da raiz no movimento vertical (intrusão ou extrusão). 


\section{CONFECÇÃO DO ARCO UTILIDADE}

$\mathrm{O}$ arco utilidade é confeccionado com fio Elgiloy azul 0,016" x 0,016" fornecido pelos fabricantes em formato de varetas. Esta liga foi desenvolvida pela Elgin Watch Company e contém $40 \%$ de cobalto, $20 \%$ de cromo, $15 \%$ de níquel, $15,8 \%$ de ferro, $7 \%$ de molibdênio, $2 \%$ de manganês, $0,16 \%$ de carbono e $0,04 \%$ de berílio ${ }^{13}$. Introduzida no mercado pela Rocky Mountain Orthodontics (Denver, Colorado, EUA), esta liga é fabricada em quatro têmperas, diferenciadas uma das outras pelas cores azul, amarelo, verde e vermelho em suas extremidades. Para confecção do arco utilidade, o fio indicado é o de ponta azul 0,016" x 0,016" sem tratamento térmico. Este fio tem a capacidade de gerar 2.000 gramas de força por milímetro quadrado, suficiente para movimentar um molar ${ }^{21}$.
Esta força pode ser diminuída, aumentando-se a distância do fio por meio de braços de alavanca. O limite elástico proporcional do fio Elgiloy azul 0,016 " x 0,016" a uma distância de $25 \mathrm{~mm}$ é de 80 gramas, e a $30 \mathrm{~mm}$ uma dobra permanente não ocorre até ultrapassar 70 gramas $^{2}$.

Para a sua confecção, inicialmente o fio é inserido no tubo do molar de um lado da boca e uma dobra de 90 graus, justaposta ao tubo em direção à gengival, é realizada (Fig. 6A). Este segmento é denominado degrau posterior e mede, aproximadamente, $5 \mathrm{~mm}$ para a mandíbula e $6 \mathrm{~mm}$ para a maxila. O degrau vertical posterior impede a deformação do arco pelas forças da oclusão e possibilita efetuar melhores movimentos nos molares e nos incisivos. Uma nova dobra de $90^{\circ}$ é realizada no fio, que segue em direção anterior (Fig. 6B),
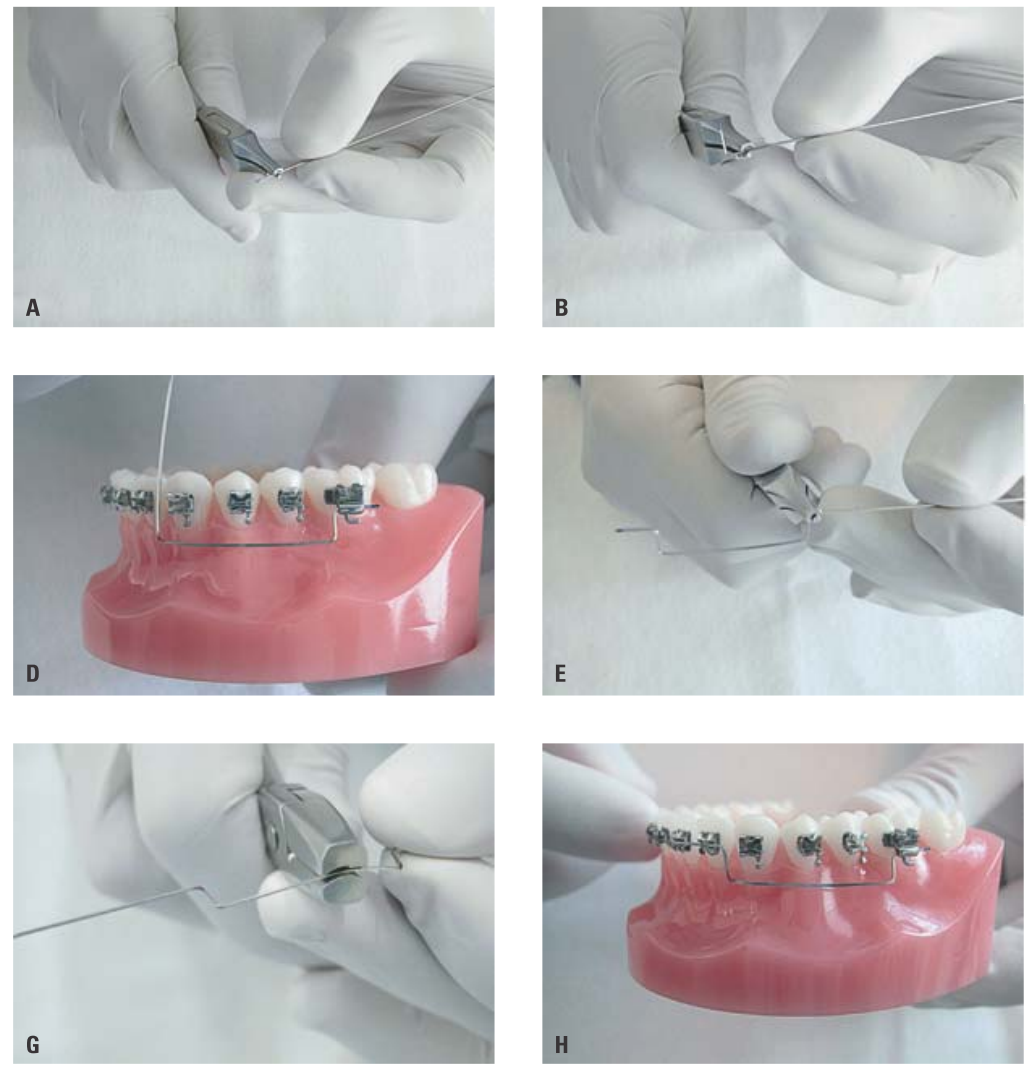

FIGURA 6 - Seqüência de confecção do arco utilidade.
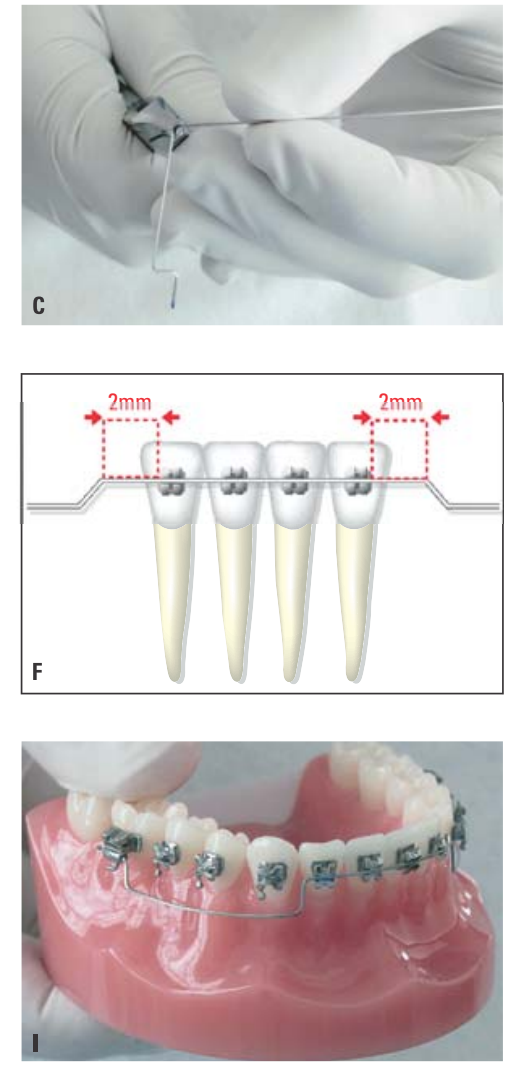

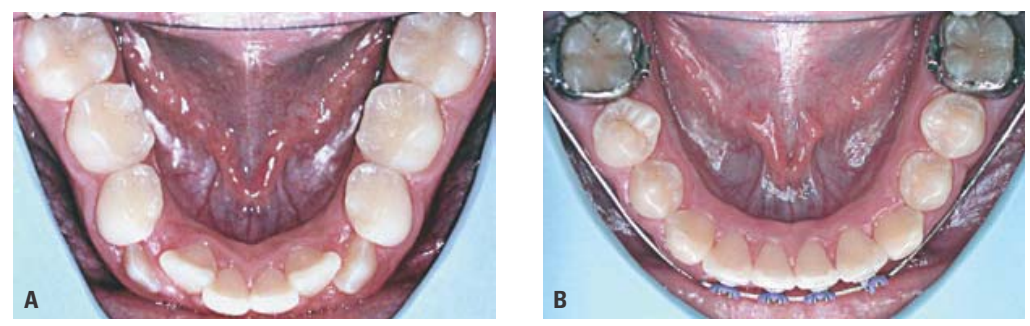

FIGURA 7 - A) Fotografia intrabucal oclusal inferior mostrando apinhamento no período da dentadura mista; B) Apinhamento corrigido com o uso do arco utilidade.

sem encostar na gengiva, e sobe passivamente em direção à distal do incisivo lateral e mesial do canino, em um ângulo de, aproximadamente, $75^{\circ}$ (Fig. 6C, D). Uma nova dobra em ângulo de $75^{\circ}$ é realizada em direção aos braquetes dos incisivos laterais, para formar o segmento anterior do arco (Fig. 6E), sendo que a altura do degrau anterior deve ser a mesma do degrau posterior. Uma sobra de $2 \mathrm{~mm}$ na distal aos braquetes dos incisivos laterais deve ser mantida para pequenos alinhamentos (Fig. 6F). Neste momento, a secção anterior deve ser contornada com um alicate "De La Rosa", para obter-se uma forma de arco ideal (Fig. 6G), e inserida nos braquetes dos incisivos (Fig. 6H). O mesmo procedimento é realizado no lado oposto (Fig. 6I) e, desta maneira, o arco utilidade está pronto.

\section{INDICAÇÕES CLÍNICAS DO ARCO UTILIDADE}

Os tipos mais comuns de arco utilidade são: arco utilidade básico, arco utilidade de retração e arco utilidade de avanço ${ }^{15}$.

\section{Arco utilidade básico}

O arco utilidade básico pode ser utilizado para manter espaço, ganhar espaço (verticalização de molares e expansão dentoalveolar), ancorar os molares e intruir os incisivos ${ }^{3}$.

\section{Manutenção de espaço}

Durante o período da dentadura mista, o arco utilidade pode ser utilizado para manter o Leeway space e solucionar problemas de apinhamento na região dos incisivos inferiores (Fig. 7).

De acordo com Gianelly ${ }^{11,12}$, o Leeway space representa a diferença entre o diâmetro mesiodistal dos segundos molares decíduos e segundos pré-molares, uma vez que o diâmetro mesiodistal dos caninos e primeiros molares decíduos é aproximadamente igual ao diâmetro mesiodistal dos caninos e dos primeiros pré-molares permanentes. $\mathrm{O}$ mesmo autor salientou que de 4 a $5 \mathrm{~mm}$ de apinhamento
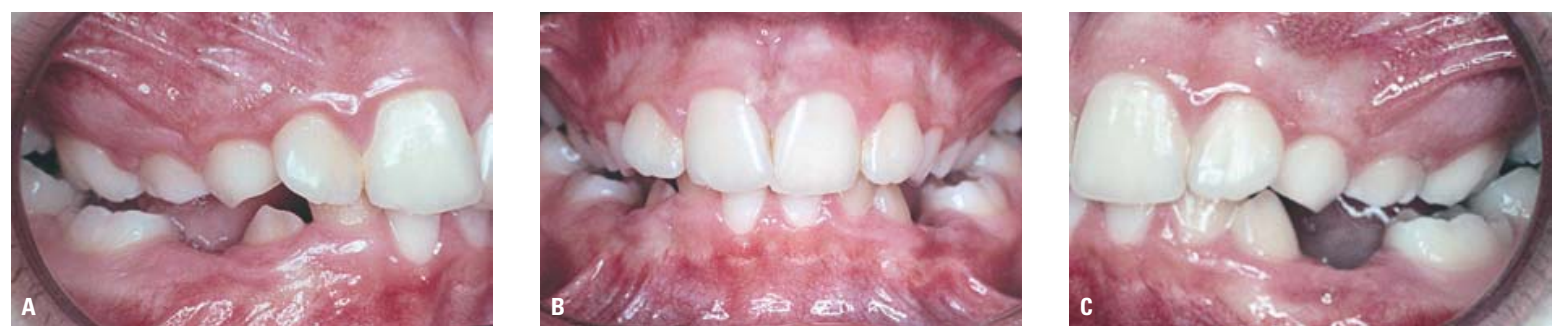

FIGURA 8 - Fotografias intrabucais obtidas no início do tratamento de uma paciente com mordida profunda e mordida cruzada bilateral posterior: A) lado direito; B) frente; C) lado esquerdo. 
dos incisivos inferiores podem ser facilmente tratados sem extrações, mantendo-se o Leeway space.

\section{Verticalização dos primeiros molares}

Quando existe uma curva de Spee profunda (Fig. 8, 9) e há condições para se verticalizar os primeiros molares permanentes, pode-se realizar uma inclinação para baixo no degrau posterior do arco utilidade (Fig. 10), com a intenção de promover a mesialização das raízes dos primeiros molares permanentes e a distalização das coroas dos mesmos primeiros molares.

Como o centro de resistência do primeiro mo- lar inferior está ligeiramente abaixo da linha amelo-cementária na parte superior da raiz mesial, a simples verticalização do primeiro molar inferior vai permitir um movimento de raiz de $2 \mathrm{~mm}$ para frente e um movimento de coroa de $2 \mathrm{~mm}$ para trás. O efeito desta movimentação é a troca de espaço no osso alveolar por um espaço no arco (Fig. 11), podendo-se chegar a $4 \mathrm{~mm}$ de aumento do perímetro do arco, ao mesmo tempo em que a curva de Spee é corrigida ${ }^{3}$ (Fig. 12, 13).

\section{Expansão dentoalveolar}

Outro meio para ganhar espaço no arco infe-

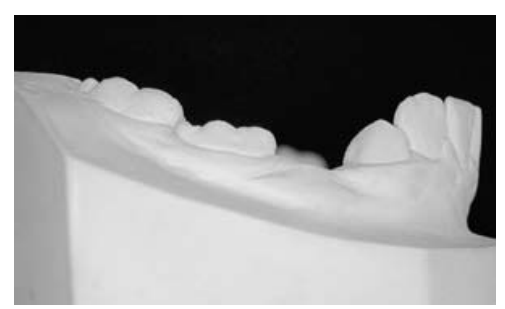

FIGURA 9 - Modelo de estudo evidenciando a curva de Spee.

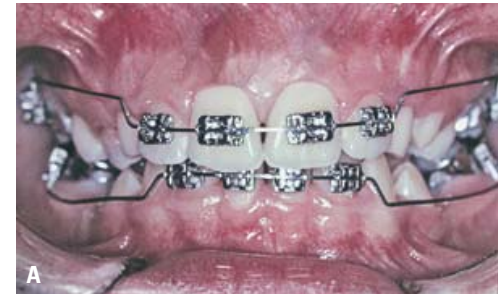

FIGURA 10 - A) Vista intrabucal do arco utilidade utilizado no tratamento. B) Ilustração da ativação no setor molar (inclinação distal) para intrusão dos incisivos e verticalização dos molares.
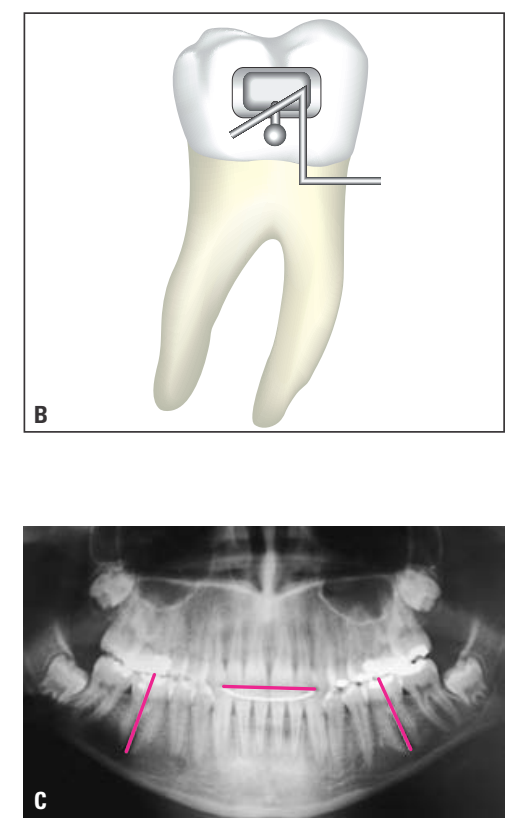

c.

B

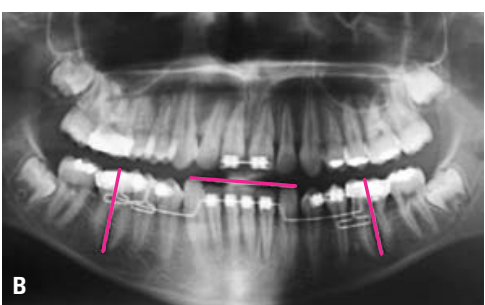

FIGURA 11 - Radiografias panorâmicas: A) inicial; B) intermediária, mostrando a verticalização dos primeiros molares permanentes e a intrusão dos incisivos inferiores: C) final.
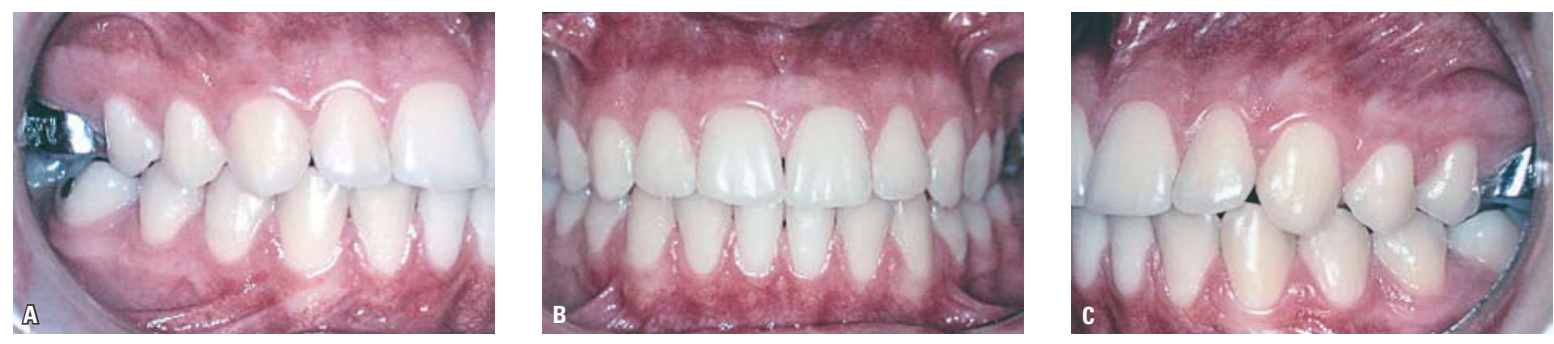

FIGURA 12 - Fotografias intrabucais finais. 

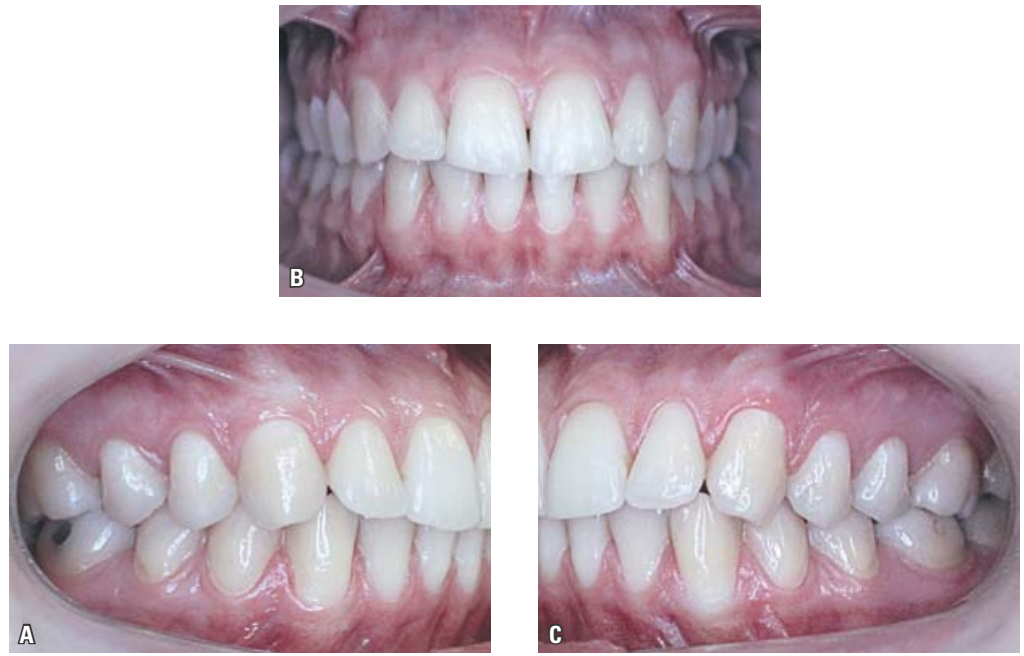

FIGURA 13 - Fotografias obtidas 10 anos e meio após o final do tratamento.

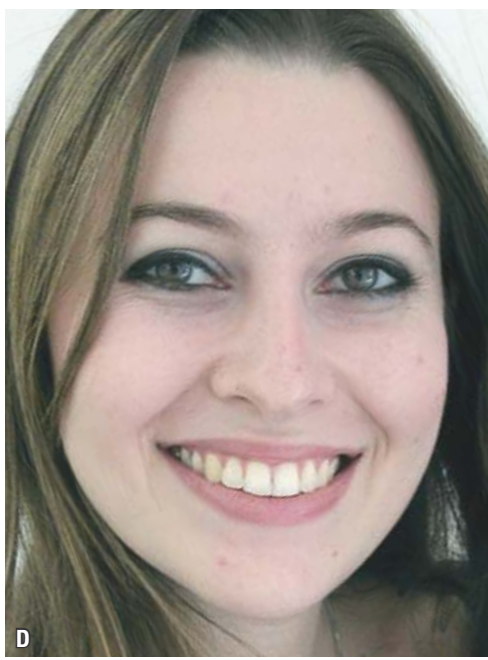

rior é a expansão dentoalveolar. De acordo com Ricketts (apud BENCH, GUGINO, HILGERS ${ }^{1}$, 1977), para cada milímetro de expansão na região dos caninos existe um ganho de $1 \mathrm{~mm}$ de comprimento de arco; para cada $1 \mathrm{~mm}$ de expansão dos pré-molares o ganho é de $0,5 \mathrm{~mm}$; e para cada $1 \mathrm{~mm}$ de expansão dos molares inferiores se ganha 1/3 de milímetro no comprimento do arco. Desta maneira, pode-se, em alguns casos, expandir o arco inferior, com o auxílio do arco utilidade (Fig. 14), e obter-se um aumento do comprimento do arco inferior.

Durante a expansão com o arco utilidade é necessário que se faça uma pré-ativação (rotação posterior em torno de 30 a $45^{\circ}$ ) na secção molar, para que ocorra o movimento controlado dos mo-
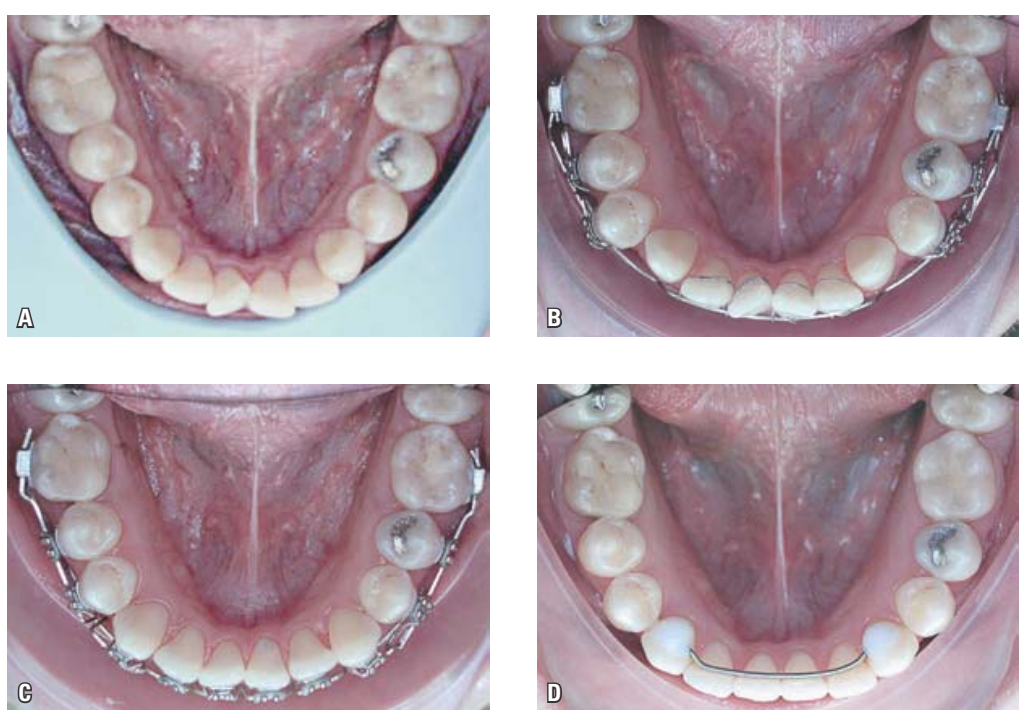

FIGURA 14 - A) Apinhamento ântero-inferior; B) expansão dentoalveolar obtida nos setores D e C com o uso do arco utilidade e arco seccional, C) expansão dentoalveolar obtida no setor B com o uso do arco utilidade e arco seccional; D) vista intrabucal oclusal ao final do tratamento. 

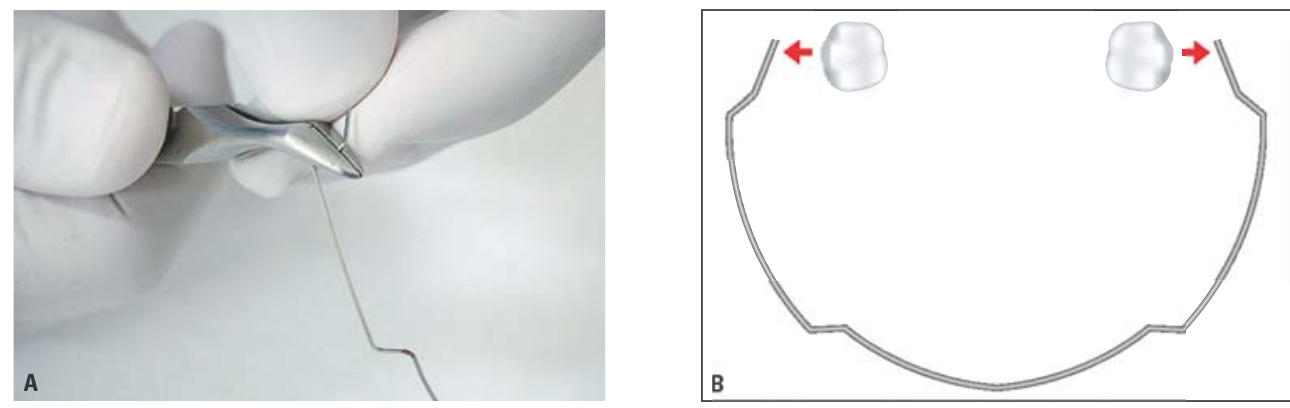

FIGURA 15 - A) Pré-ativação (rotação posterior de 30 a $45^{\circ}$ ) no setor molar do arco utilidade, utilizando-se os dedos e um alicate Weingart, B) ilustração do arco utilidade com a ativação de rotação posterior e expansão.
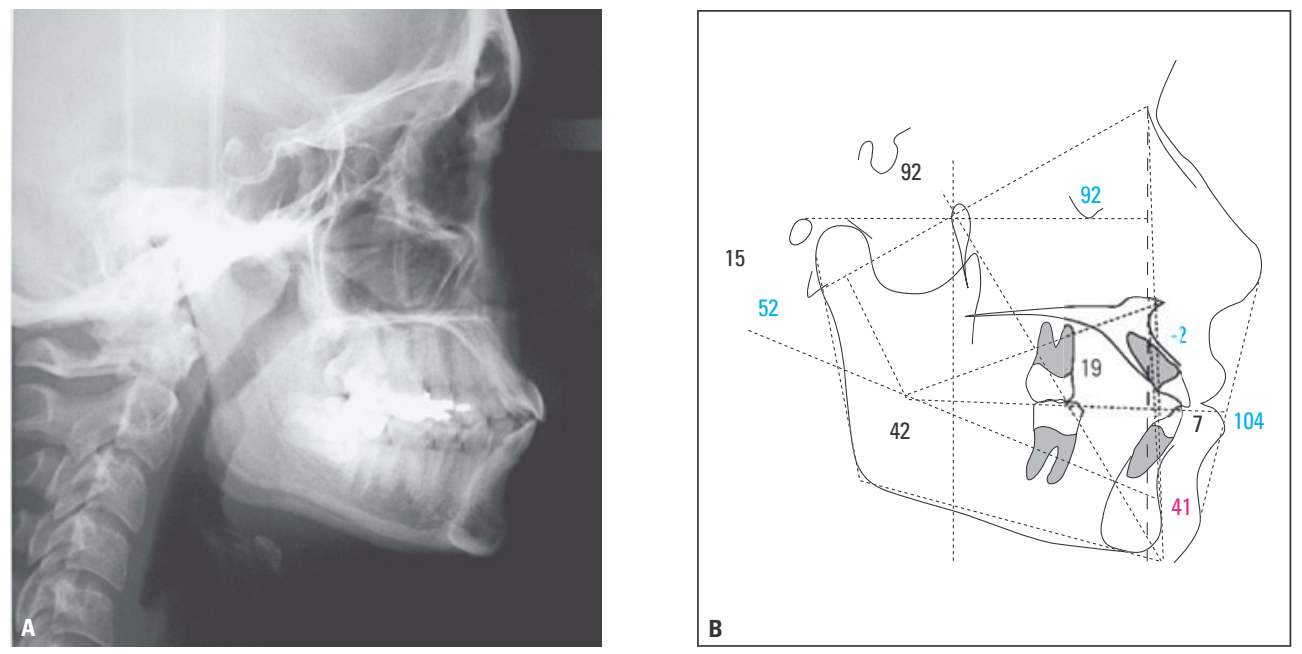

FIGURA 16 - A) Radiografia cefalométrica inicial; B) traçado cefalométrico inicial de Ricketts.
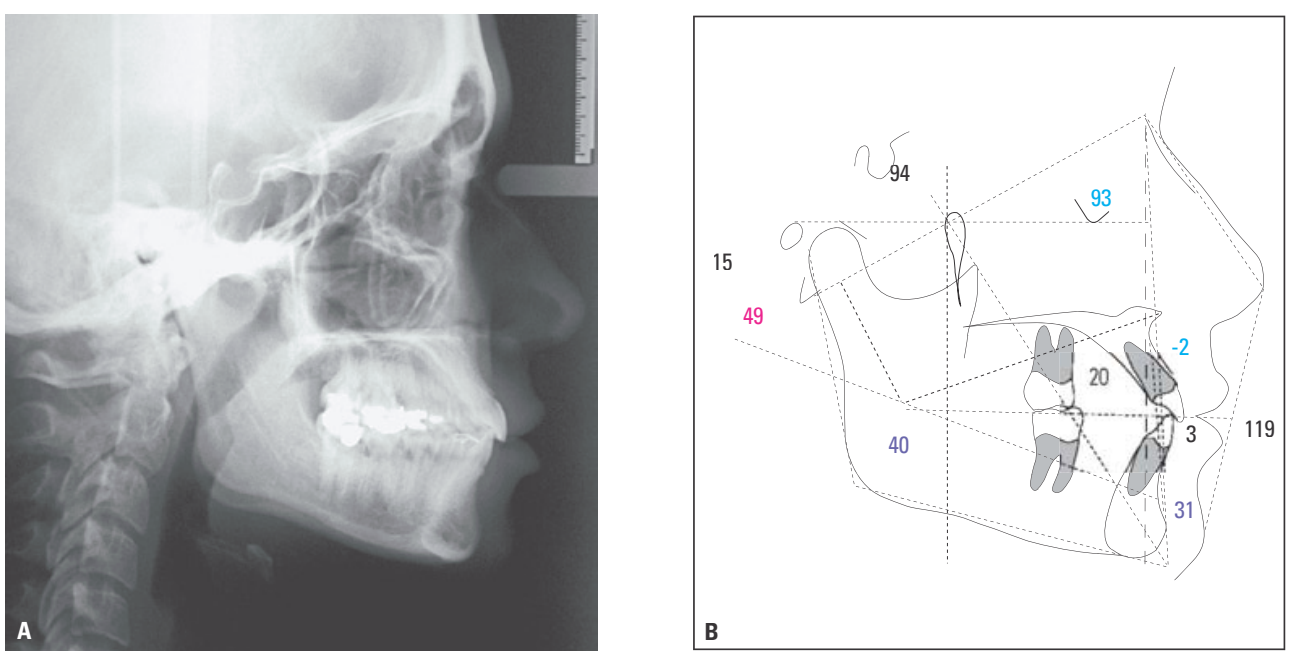

FIGURA 17 - A) Radiografia cefalométrica final; B) traçado cefalométrico final de Ricketts. 
lares durante a expansão (Fig. 15).

Além de obter espaço no arco inferior para corrigir apinhamentos, a expansão dentoalveolar pode, em alguns casos, ser utilizada para corrigir a biprotrusão dentoalveolar. As telerradiografias de perfil e os cefalogramas (Fig. 16, 17) do início e do final do tratamento demonstram o efeito desta mecânica em uma paciente do gênero feminino com 22 anos e 5 meses de idade, com má oclusão de Classe I, biprotrusão dentoalveo- lar e suave apinhamento na região dos incisivos superiores.

A redução da biprotrusão dentoalveolar pode ser observada cefalometricamente por meio da alteração do ângulo interincisivos (inicial de $104^{\circ}$ e final de $119^{\circ}$ ), redução da protrusão do incisivo inferior em relação à linha 1-Apo (inicial de $7 \mathrm{~mm}$ e final de $3 \mathrm{~mm}$ ) e diminuição do IMPA de $112^{\circ}$ para $101^{\circ}$.

Esta mudança no posicionamento inicial e final
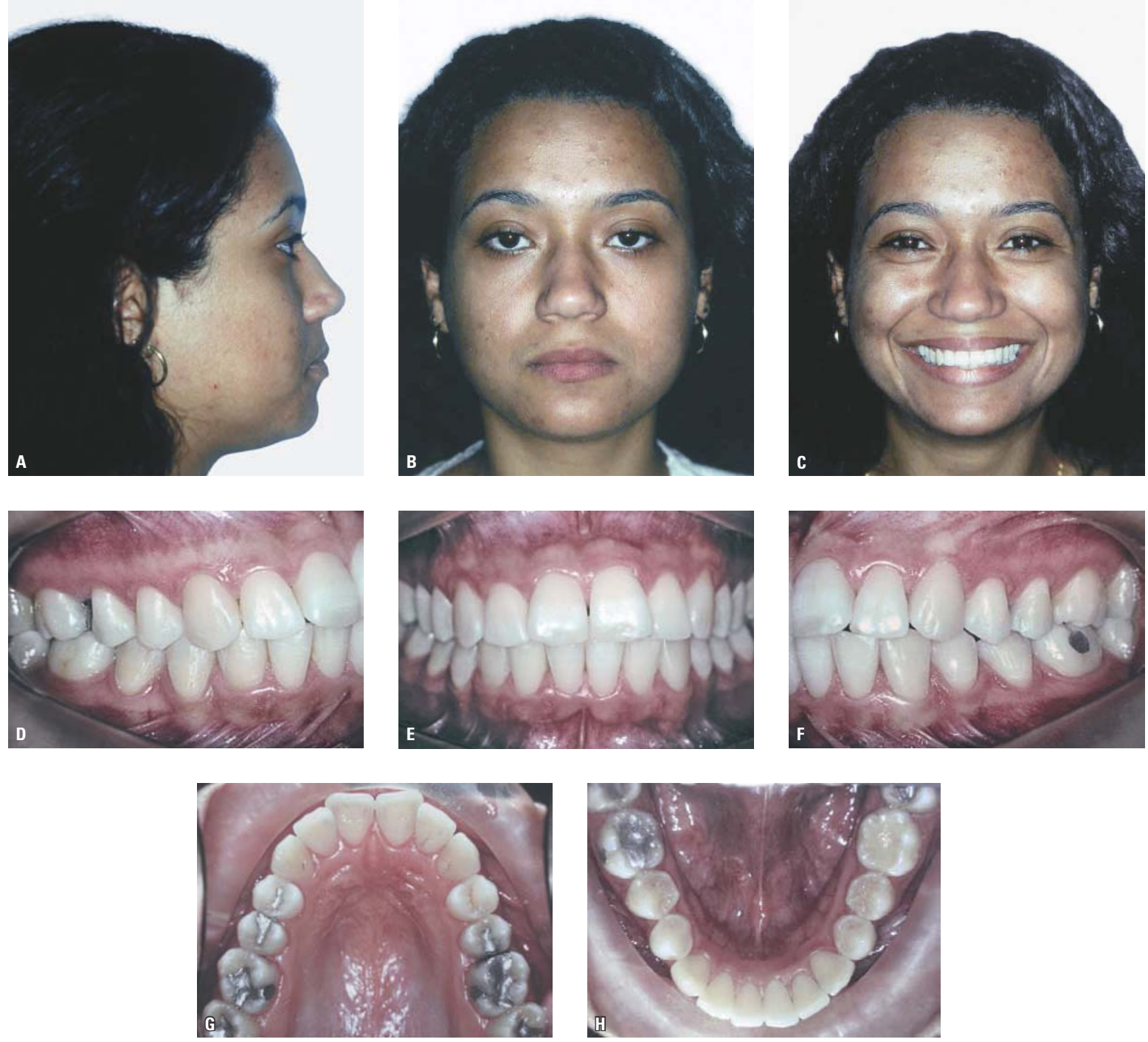

FIGURA 18 - Fotografias obtidas no início do tratamento. 

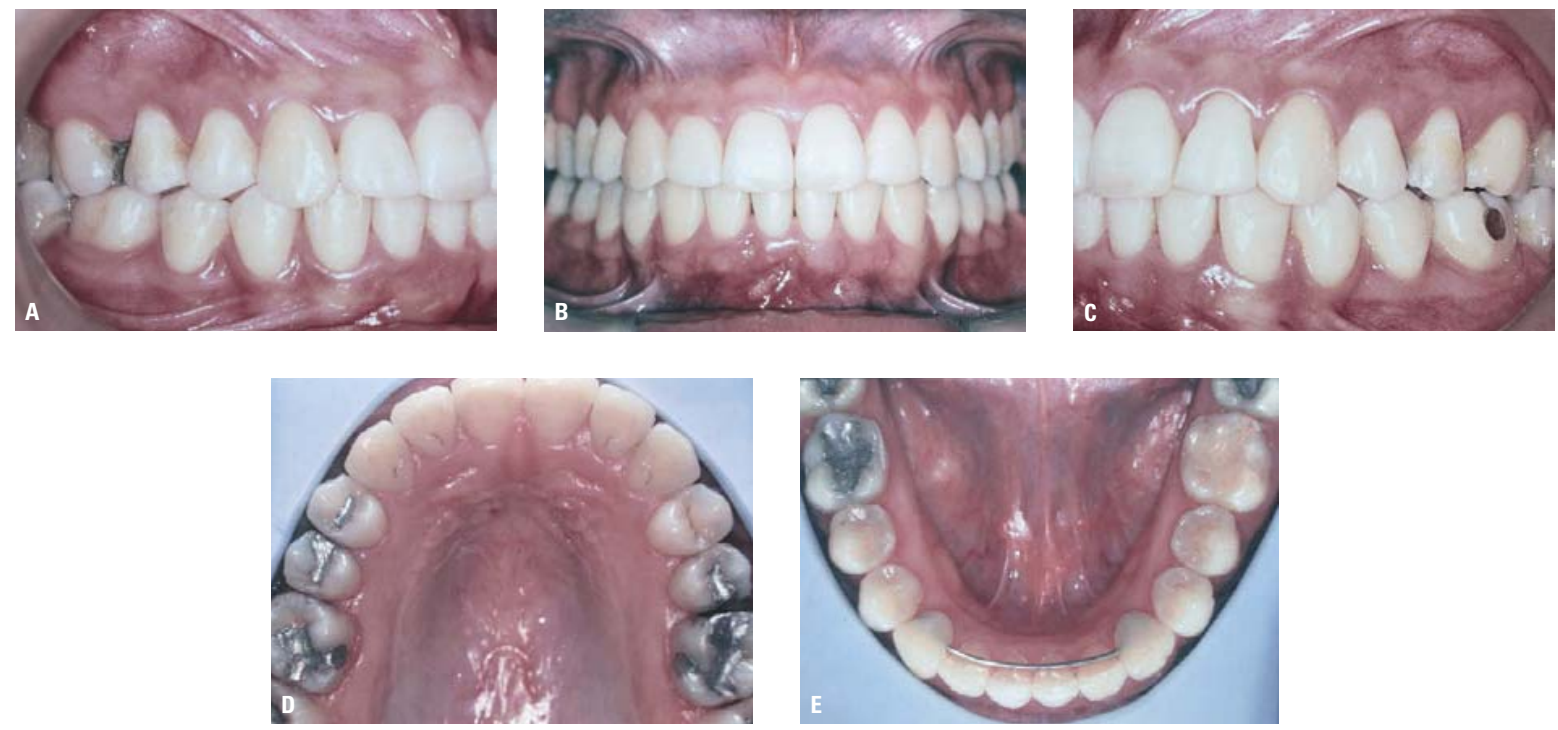

FIGURA 19 - Fotografias intrabucais obtidas no final do tratamento.

dos incisivos inferiores indica um ganho de espaço de $8 \mathrm{~mm}$. As fotografias extrabucais e intrabucais obtidas no início do tratamento (Fig. 18), intrabucais do final do tratamento (Fig. 19) e extrabucais e intrabucais obtidas 8 anos após o final do tratamento (Fig. 20) demonstram uma excelente estética facial e uma oclusão morfologicamente correta.

\section{Ancoragem inferior}

$\mathrm{O}$ arco utilidade básico pode também ser utilizado para ancorar os molares inferiores em tratamentos com extrações de pré-molares e, também, para suportar os efeitos colaterais dos elásticos de Classe II. Para tanto, a terapia Bioprogressiva recomenda que as raízes dos primeiros molares inferiores sejam colocadas contra o osso cortical vestibular denso. Este tipo de osso possui poucos vasos sanguíneos, fator chave para a "ancoragem cortical”, pois os elementos celulares responsáveis pela reabsorção e aposição óssea são transportados pelo sangue. Como no osso cortical o suprimento de sangue é limitado, o processo biológico necessário para o movimento dos dentes é mais lento.

Cook, Sellke e Begole ${ }^{6}$ realizaram um estudo com o objetivo de analisar o controle da dimensão vertical durante a correção da Classe II, divisão 1, em pacientes tratados na fase de crescimento. Três grupos foram analisados: grupo 1, tratado com uma combinação de extrabucal cervical e arco utilidade inferior; grupo 2, tratado somente com um extrabucal cervical e grupo 3 (controle), que não recebeu tratamento. As conclusões deste estudo, com relação ao uso do arco utilidade inferior foram: houve intrusão de incisivos inferiores com inclinação e sem avanço, enquanto os molares inferiores inclinaram distalmente sem extrusão. Segundo os autores, pode ser possível que a ancoragem cortical utilizada no tratamento tenha evitado a extrusão dos molares. Não houve diferença estatisticamente significante com relação à rotação mandibular horária.

Ülger et al. ${ }^{28}$ realizaram, em 2006, o mesmo tipo de estudo de Cook, Sellke e Begole ${ }^{6}$ e chegaram à conclusão de que o arco utilidade produz intrusão, retrusão e inclinação lingual dos incisivos inferiores. Também neste estudo, o uso conjunto do extrabucal cervical e arco utilidade não promoveu o aumento do ângulo do plano mandibular. Os autores alegam que este fato ocorreu em razão do aumento estatisticamente significante ocorrido 

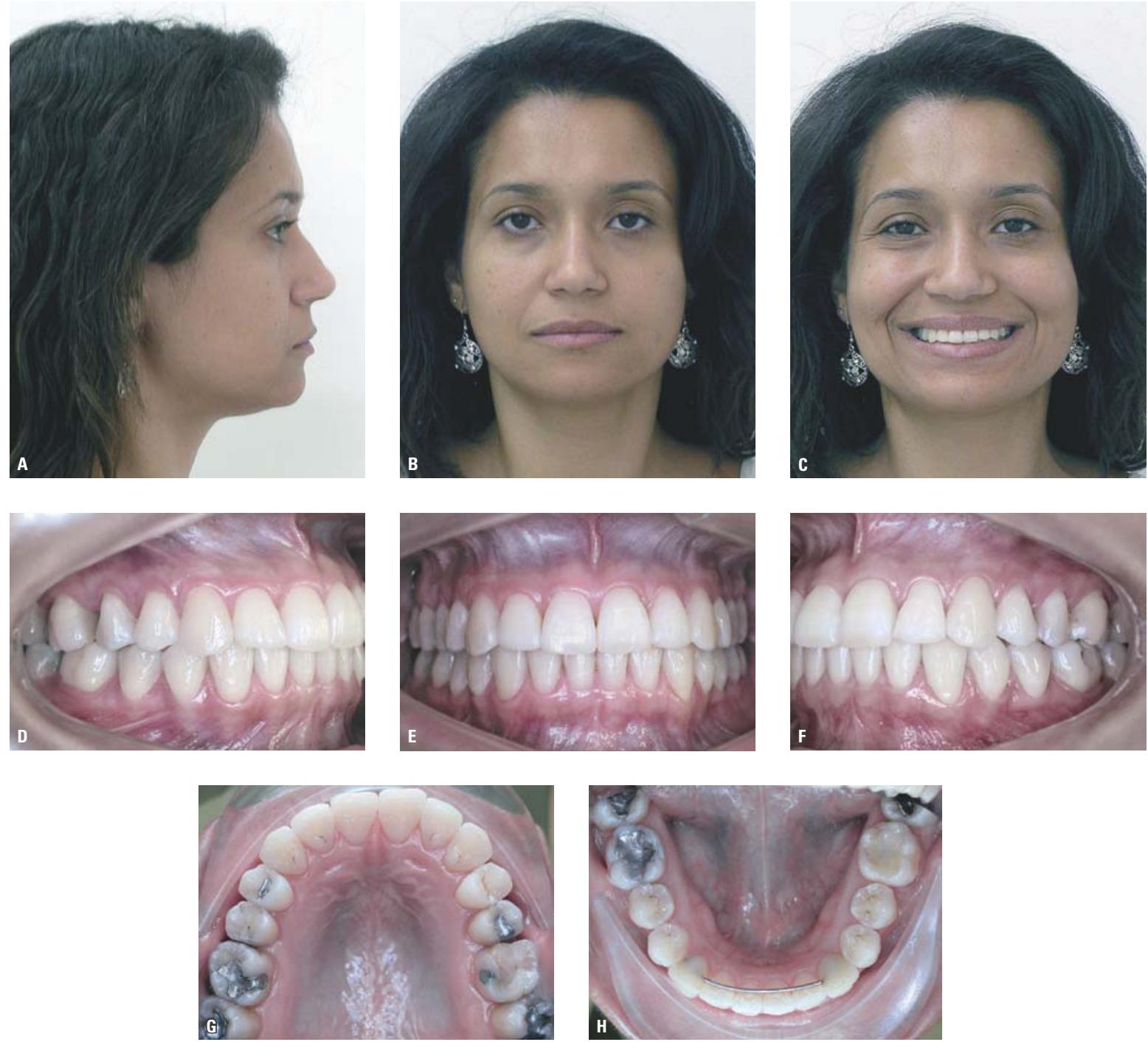

FIGURA 20 - Fotografias obtidas 8 anos após o final do tratamento.

na altura do ramo mandibular durante o estudo. A amostra avaliada constituiu-se de 24 indivíduos com má oclusão do tipo Classe II, divisão 1 esquelética com padrão de crescimento facial normal ou hiperdivergente. Metade da amostra foi tratada com extrabucal cervical e arco utilidade e a outra metade somente com extrabucal cervical. Os grupos tratados foram comparados com uma amostra controle de 12 indivíduos que não receberam nenhum tratamento.
Ellen, Schneider e Sellke ${ }^{7}$ estudaram a eficiência da ancoragem cortical, comparando dois grupos de pacientes com má oclusão de Classe II, tratados com mecânica de Classe II: o grupo 1 utilizou o arco utilidade; o grupo 2 utilizou aparelho total com a técnica Edgewise. O resultado deste estudo demonstrou que não houve diferença estatisticamente significante entre os dois grupos. Embora a ancoragem cortical não tenha retardado o movimento dos molares inferiores, ela não 

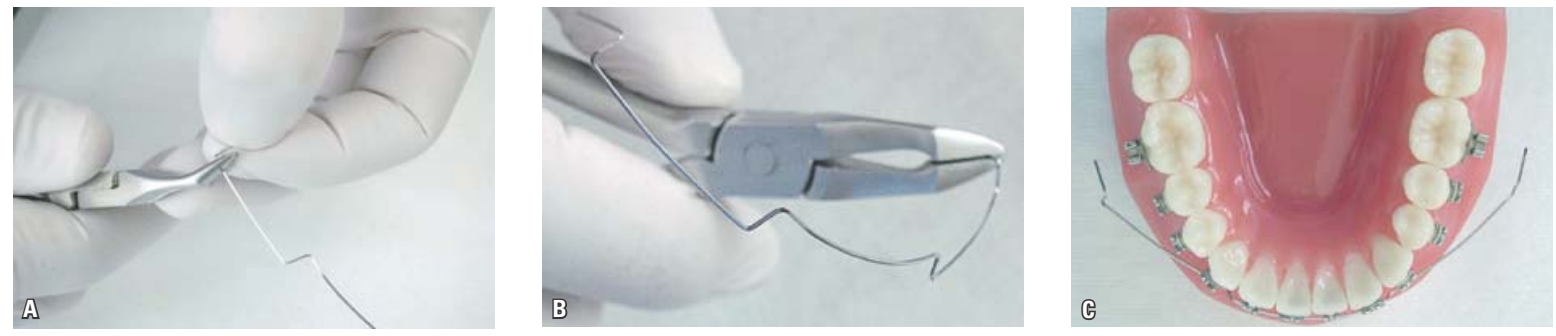

FIGURA 21 - A) Pré-ativação (torque vestibular de raiz de 30 a 45\%) realizada com o auxílio de um alicate Weingart; B) angulação sendo conferida com um alicate Weingart; C) vista oclusal do arco utilidade após as ativações para ancoragem cortical.

foi menos efetiva com montagem parcial, contra a montagem total do aparelho.

Urias e Mustafa ${ }^{29}$ não encontraram diferença estatisticamente significante entre a técnicas Bioprogressiva e Straight wire no controle de ancoragem inferior. Entretanto, a média de perda de ancoragem inferior na técnica Bioprogressiva, utilizando somente os incisivos inferiores e os primeiros molares, foi de $3,1 \mathrm{~mm}$, enquanto na técnica Straight wire, utilizando montagem total dos aparelhos, foi de $4 \mathrm{~mm}$.

A ativação para a ancoragem cortical pode ser realizada com o auxílio do alicate Weingart (Fig. 21A). A figura 21B demonstra o torque radicular vestibular de $45^{\circ}$ inserido na secção molar por meio desta ativação. $\mathrm{O}$ torque vestibular das raízes dos primeiros molares inferiores, juntamente com a ativação de expansão de $5 \mathrm{~mm}$ de cada lado (Fig. 21C), coloca este dente próximo à cortical vestibular da linha obliqua externa, promovendo a denominada ancoragem cortical. Este procedimento é um dos dogmas da "Ciência Bioprogressiva" de Ricketts, que advoga colocar as raízes distantes do osso cortical (menos vascularizado) quando se deseja o movimento eficiente, e contra o osso cortical quando a ancoragem é desejada ${ }^{1}$.

A eficiência desta mecânica é mostrada a seguir, por meio de um caso clínico tratado com extrações de dois primeiros pré-molares superiores e dois segundos pré-molares inferiores, em uma paciente do gênero feminino com 40 anos de idade e padrão facial do tipo dolicofacial (Fig. 22, 23, 24). A paciente apresentava, ao início do tratamento, uma má oclusão do tipo Classe II esquelética (convexidade $=6 \mathrm{~mm}$ ) compensada pela protrusão dos incisivos inferiores ( 1 -Apo $=8 \mathrm{~mm}$ ) e retrusão dos incisivos superiores, mordida cruzada posterior do lado direito, mordida aberta anterior e sorriso gengival.

A avaliação cefalométrica (Fig. 25A, B) mostrou uma redução na convexidade facial de $6 \mathrm{~mm}$ para $5 \mathrm{~mm}$ e uma diminuição no valor de 1-Apo de $8 \mathrm{~mm}$ para $1 \mathrm{~mm}$. Esta modificação significa que os inferiores foram retraídos $7,5 \mathrm{~mm}$, pois a modificação da convexidade afeta (aumenta a metade) o valor de 1-Apo. Portanto, $15 \mathrm{~mm}$ de aumento no perímetro do arco foram obtidos com a mecânica utilizada.

A análise das sobreposições cefalométricas de Rickets demonstra, em detalhes, as modificações ocorridas durante o tratamento ${ }^{9}$ (Fig. 26-30).

\section{Intrusão de incisivos}

Embora o arco utilidade sirva para muitas funções, certamente a mais conhecida é a capacidade do mesmo realizar a intrusão dos incisivos. Após a sua ativação, o arco utilidade gera uma força leve e contínua, que é transmitida aos incisivos por meio dos braços de alavanca.

A ativação para intrusão dos incisivos inferiores é realizada com o auxílio do alicate Weingart, que deve apoiar o degrau posterior do arco utilidade. 

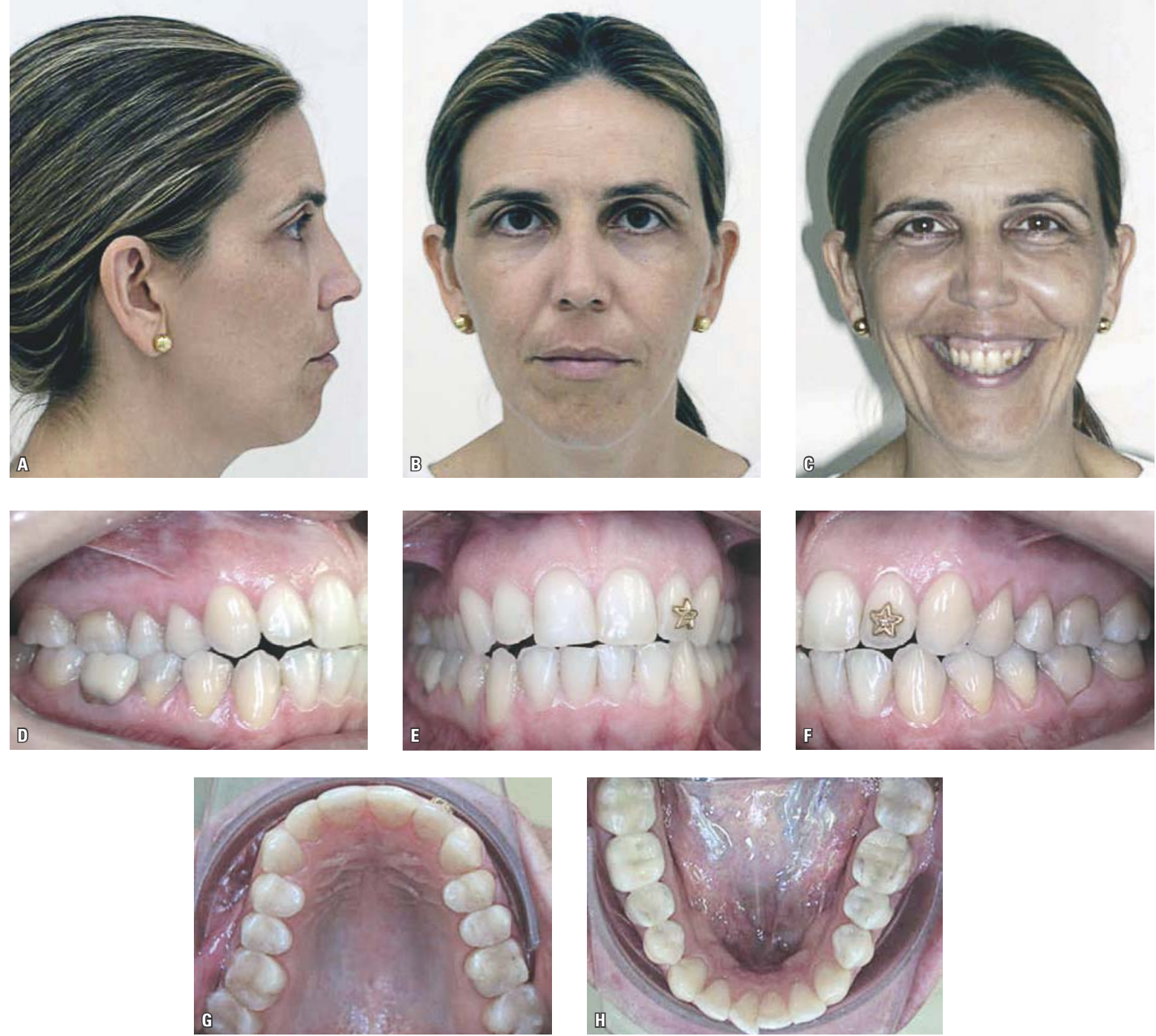

FIGURA 22 - Fotografias extrabucais e intrabucais do início do tratamento.
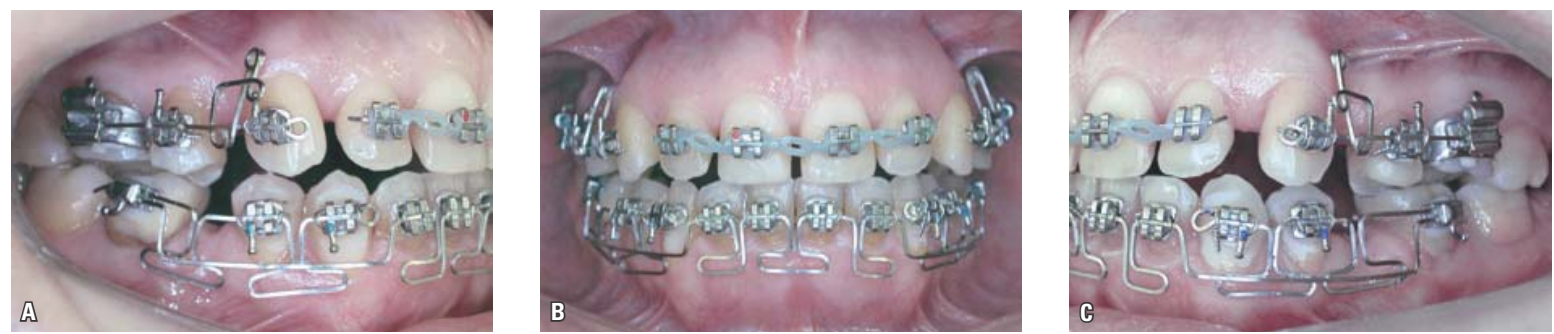

FIGURA 23 - Fotografias intrabucais obtidas durante a mecânica: A) arco seccional duplo "T" de nivelamento inferior e arco seccional para retração do dente 13 modificado por Masato Nobuyasu; B) arco utilidade de nivelamento inferior e arco seccional 0,016" x 0,016" Elgiloy com elásticos em corrente para fechar espaços entre os incisivos; C) arco seccional duplo "T" de nivelamento inferior e arco seccional para retração do dente 23 modificado por Masato Nobuyasu. 

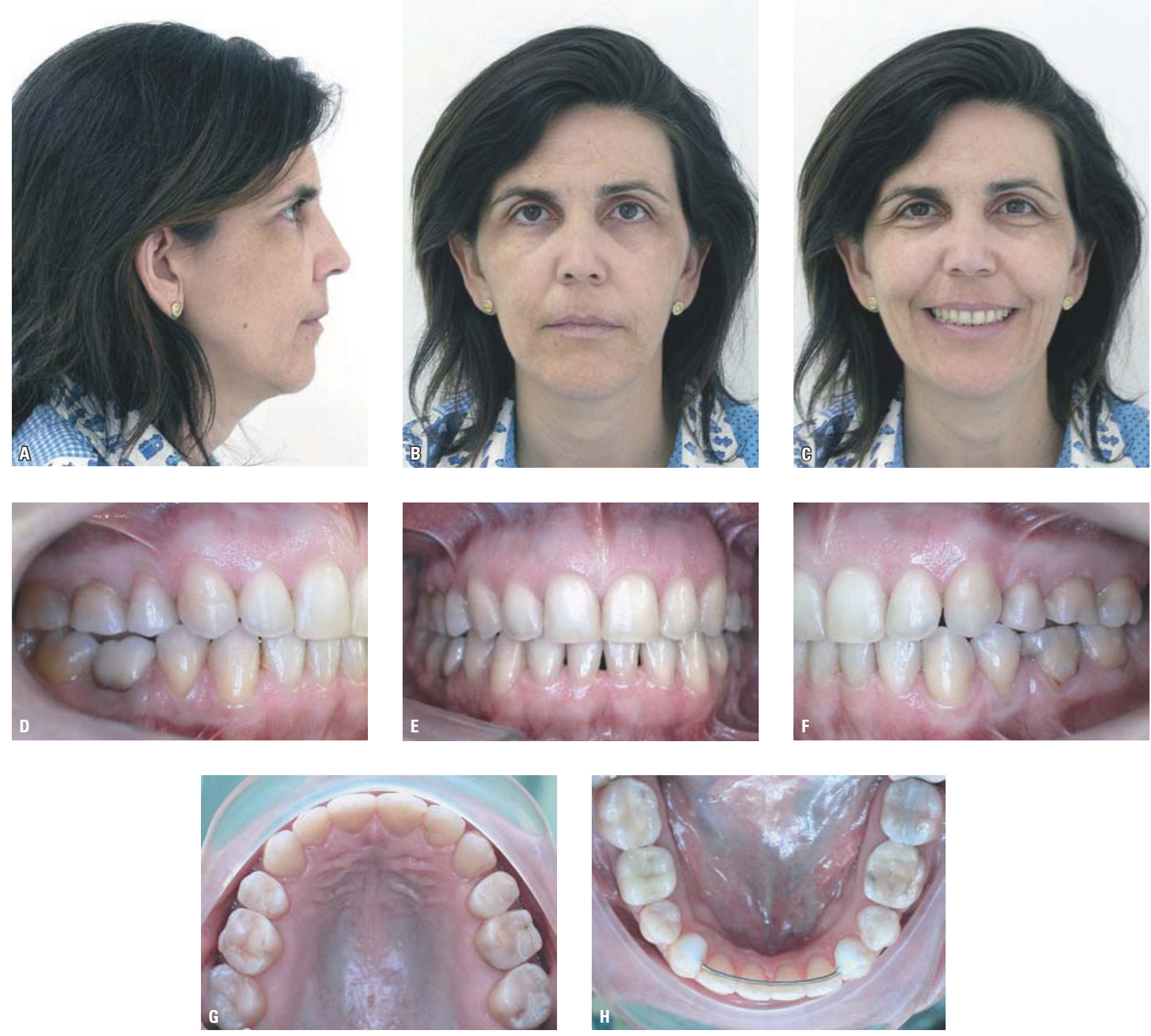

FIGURA 24 - Fotografias extrabucais e intrabucais do final do tratamento.
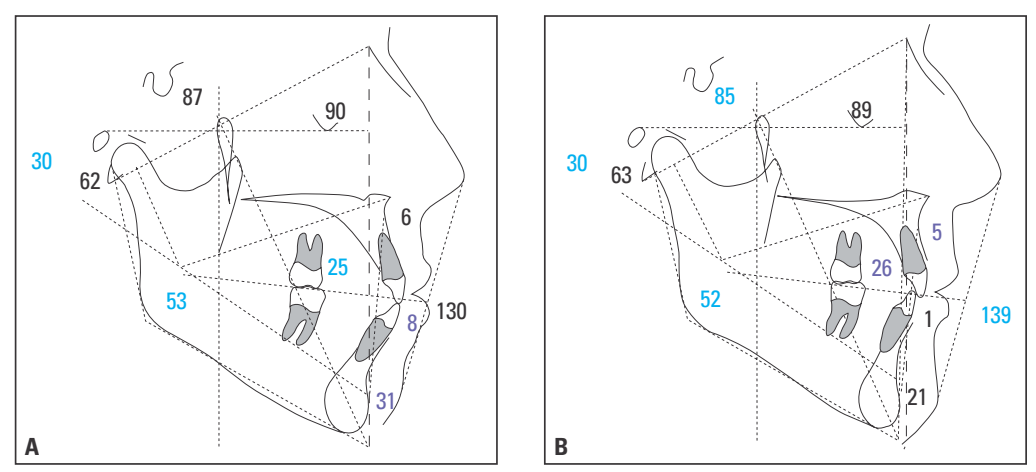

FIGURA 25 - Análise cefalométrica de Ricketts: A) inicial; B) final. 


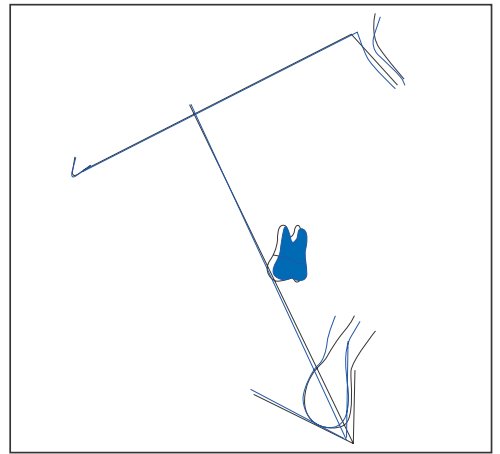

FIGURA 26 - Sobreposição cefalométrica na linha básio-násio com o centro em CC (Inicial-preto e final-azul), utilizada para avaliar a alteração no posicionamento espacial da mandíbula. Pode-se observar, neste caso, que a mandíbula girou $2^{\circ}$ no sentido horário.

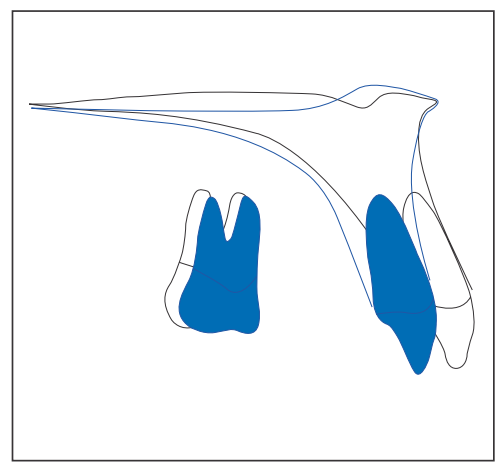

FIGURA 28 - Sobreposição cefalométrica no plano palatino (ENA- ENP) com o centro em ENA (Inicialpreto e final-azul), utilizada para avaliar as alterações ocorridas nos incisivos e nos primeiros molares superiores. Pode-se observar a retração dos incisivos, sem extrusão e de corpo (controle de torque), e a mesialização dos molares sem extrusão.

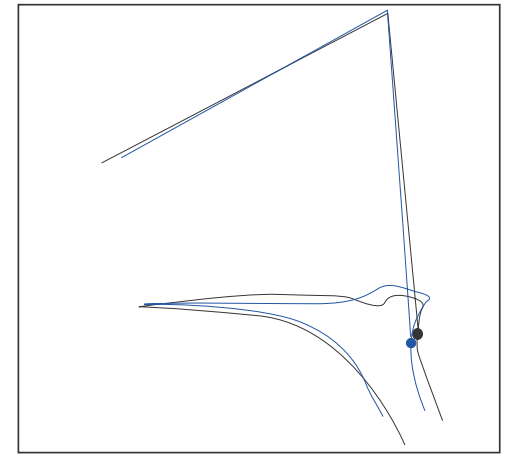

FIGURA 27 - Sobreposição cefalométrica na linha básio-násio com o centro em Násio (Inicial-preto e final-azul), utilizada para avaliar a alteração no posicionamento espacial da maxila. Pode-se observar, neste caso, que o ponto $A$ (referência da maxila) sofreu deslocamento de $1 \mathrm{~mm}$ para distal.

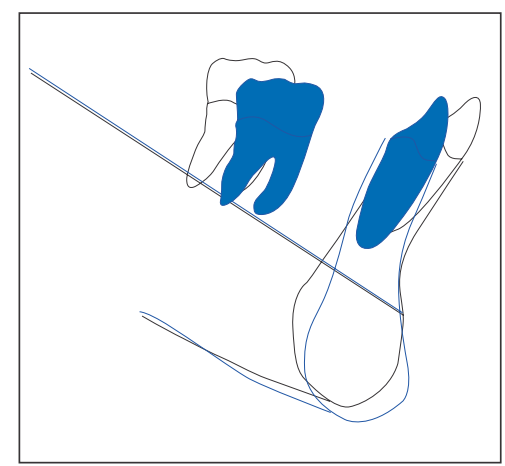

FIGURA 29 - Sobreposição cefalométrica no plano Xi-Pm com o centro em Pm (Inicial-preto e finalazul), utilizada para avaliar as alterações nos incisivos e nos primeiros molares inferiores. Pode-se observar a retração e intrusão dos incisivos e a mesialização e intrusão dos molares.

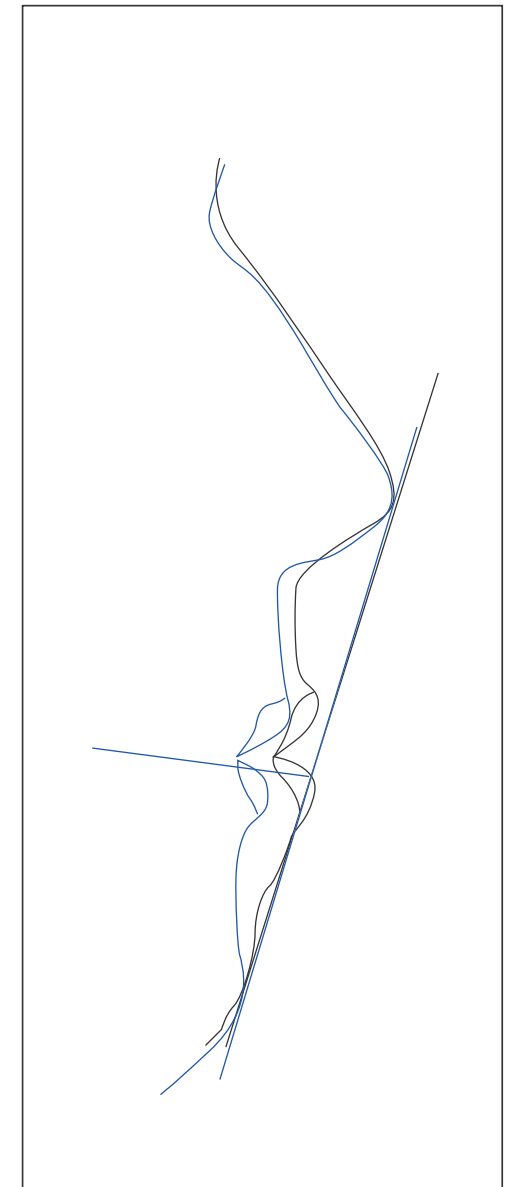

FIGURA 30 - Sobreposição cefalométrica na linha estética de Ricketts e plano oclusal (Inicial-preto e final-azul), utilizada para avaliar as alterações no perfil tegumentar. Pode-se observar uma retração dos lábios superior e inferior, em relação à linha estética.
Com o apoio dos dedos, a secção molar é inclinada para baixo entre $30^{\circ}$ e $45^{\circ}$ (Fig. 31 A, B).

Com esta ativação, o arco utilidade deve promover uma força entre $70 \mathrm{~g}$ e $80 \mathrm{~g}$ para os quatro incisivos inferiores (Fig. 31C).

Como a força gerada pelo arco utilidade chega primeiro aos incisivos laterais, uma suave curva para baixo deve ser realizada na região dos incisivos centrais inferiores, para que os quatro dentes recebam uma força semelhante (Fig. 32).
O torque lingual de coroa no setor anterior (incisivos inferiores) não é necessário, pois a ação de inclinação posterior dos molares inferiores promove a verticalização dos incisivos inferiores. Quando somente a intrusão dos incisivos inferiores for o objetivo da mecânica, a ativação de intrusão dos incisivos não deve ser realizada até que os molares estejam ancorados (ancoragem cortical). Neste caso, um torque lingual de coroa de $5^{\circ}$ no setor anterior deve ser realizado, com o objetivo de co- 

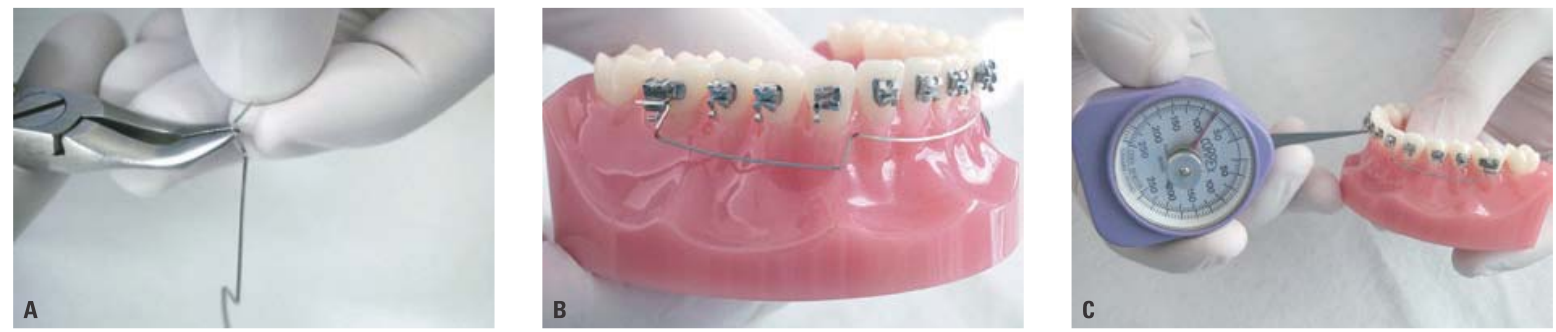

FIGURA 31 - A) Pré-ativação (inclinação distal de 30 a 45ํ) realizada com o auxílio de um alicate Weingart. B) Efeito da ativação. C) Medição da força utilizada (80 gramas).

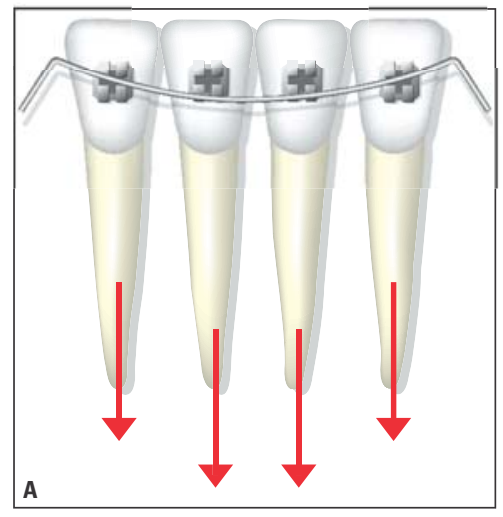

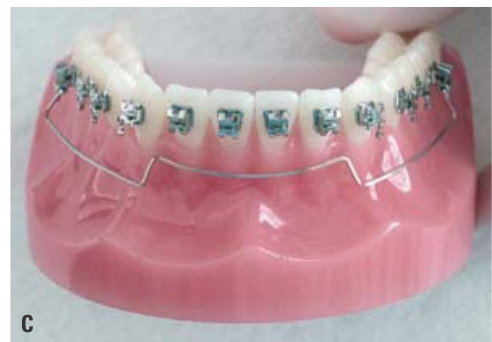

FIGURA 32 - A) Esquema demonstrando que uma suave curva no setor dos incisivos inferiores distribui, para os 4 incisivos, de maneira homogênea, a força exercida pelo arco utilidade. B) Pré-ativação do setor incisivo com 0 auxílio de um alicate De La Rosa. C) Efeito da ativação.

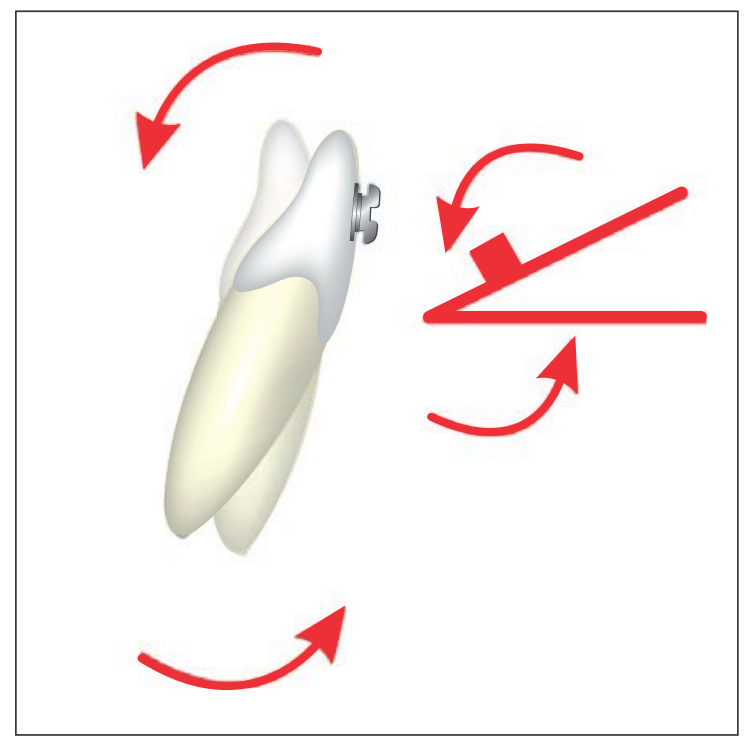

FIGURA 33 - Torque vestibular de raiz, utilizado, quando necessário, para mover o ápice dos incisivos inferiores para fora da cortical óssea lingual. locar as raízes dos incisivos para fora da cortical lingual (Fig. 33).

Segundo Ricketts ${ }^{25}$, o posicionamento correto dos incisivos inferiores reside no gerenciamento do plano oclusal funcional. O torque deveria ser inserido no setor dos incisivos somente em situações especiais.

Após a intrusão dos incisivos inferiores com o uso do arco utilidade, o canino pode ser intruído com um fio elástico com 35 gramas. A intrusão dos caninos inferiores deve evitar o osso cortical, para se obter um movimento eficiente. O elástico unido ao arco utilidade inferior permite liberdade de movimento das raízes dos caninos durante a intrusão ${ }^{2}$. O objetivo desta mecânica é colocar os caninos e incisivos inferiores no mesmo nível dos pré-molares inferiores (Fig. 34). 

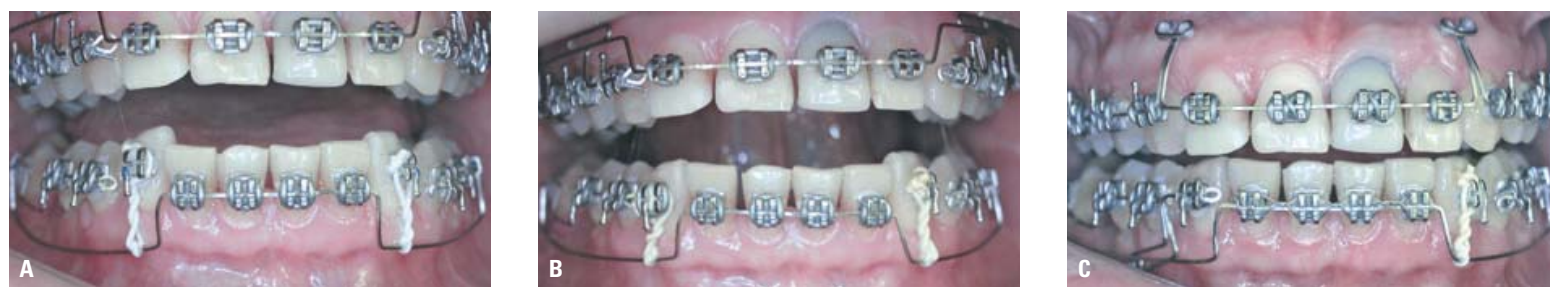

FIGURA 34 - A) Início da intrusão dos caninos inferiores com um fio de seda; B) durante a intrusão; C) intrusão dos caninos inferiores finalizada. Do lado direito podese observar um arco seccional sendo utilizado para verticalizar a raiz do dente 43 .

Indicações para intrusão dos incisivos inferiores

A intrusão dos incisivos inferiores é, geralmente, realizada nos casos de Classe II, $1^{\text {a }}$ e $2^{\text {a }}$ divisões. Estes pacientes, via de regra, apresentam uma curva de Spee acentuada e a intrusão dos incisivos inferiores é um dos objetivos do tratamento. O trespasse horizontal acentuado presente na má oclusão do tipo Classe II, $1^{\text {a }}$ divisão, propicia a extrusão dos incisivos inferiores, por falta de contato destes com os seus antagonistas, e pode ser a razão da excessiva erupção destes dentes. Já a má oclusão do tipo Classe II, $2^{a}$ divisão, apresenta um ângulo interincisivos aumentado (geralmente acima de $140^{\circ}$ ), o que também favorece a extrusão dos incisivos superiores e inferiores, e a instalação de uma mordida profunda.

Independente do tipo de má oclusão, a "ciência

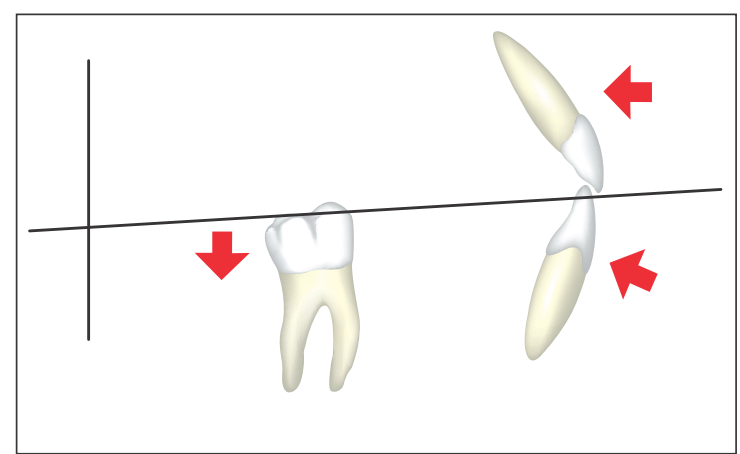

FIGURA 35 - Esquema demonstrando a relação entre o plano oclusal e o posicionamento dos dentes. 0 abaixamento posterior do plano oclusal automaticamente retrai os incisivos.
Bioprogressiva" recomenda que os incisivos inferiores sejam intruídos sempre que estes dentes estejam acima do plano oclusal funcional (linha que passa entre a superfície oclusal dos pré-molares e molares permanentes).

De acordo com Ricketts ${ }^{25}$, o plano oclusal funcional deve passar abaixo ou no mesmo nível do ponto Xi. Desta maneira pode-se evitar interferências durante o movimento de corte dos alimentos, além de permitir um crescimento normal da mandíbula. Pacientes que apresentem o plano oclusal funcional acima do ponto Xi podem se beneficiar da utilização do arco utilidade inferior e do extrabucal cervical. Estes aparelhos podem promover o abaixamento posterior do plano oclusal e a retração dos incisivos inferiores (Fig. 35).

Esta ação beneficia o tratamento das más oclu-

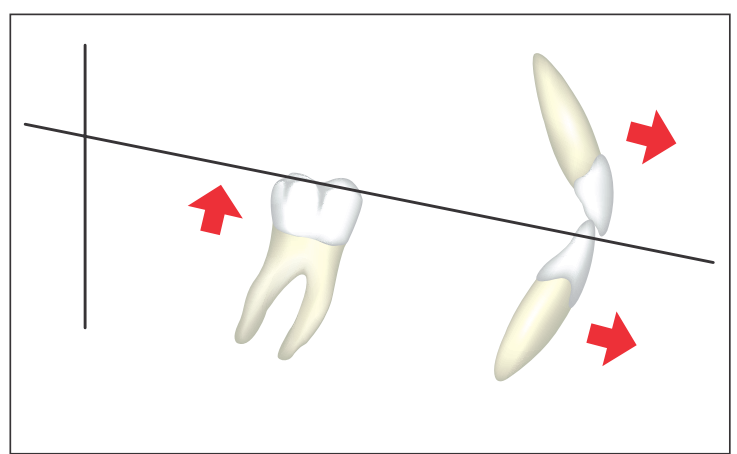

FIGURA 36 - Esquema demonstrando a relação entre o plano oclusal e o posicionamento dos dentes. 0 levantamento posterior do plano oclusal automaticamente avança os incisivos. 
sões do tipo Classe II, pois "destrava" a mandíbula para que a mesma possa crescer normalmente para a frente. Ao contrário, a extrusão dos molares inferiores (Fig. 36) inclina o plano oclusal na região posterior, fato que colabora para o "travamento" da mandíbula, além de avançar os incisivos inferiores.

\section{Arco utilidade de retração}

$\mathrm{O}$ arco utilidade de retração, ou de consolidação dos incisivos (Fig. 37), consiste em uma modificação do arco utilidade básico, realizada por meio da adição de oito helicóides, que são colocados nas extremidades do degrau vertical posterior, anterior e na ponte lateral ${ }^{8}$. Estes he-
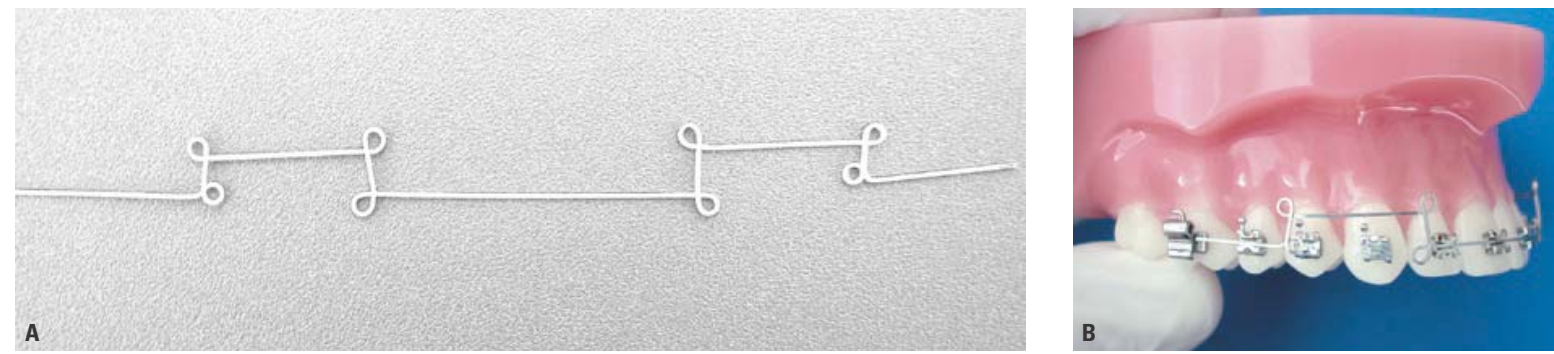

FIGURA 37 - A) Arco utilidade de retração dos incisivos, confeccionado com 8 hélicóides, para uma ação de força mais suave e constante. B) Arco inserido no tubo triplo superior.
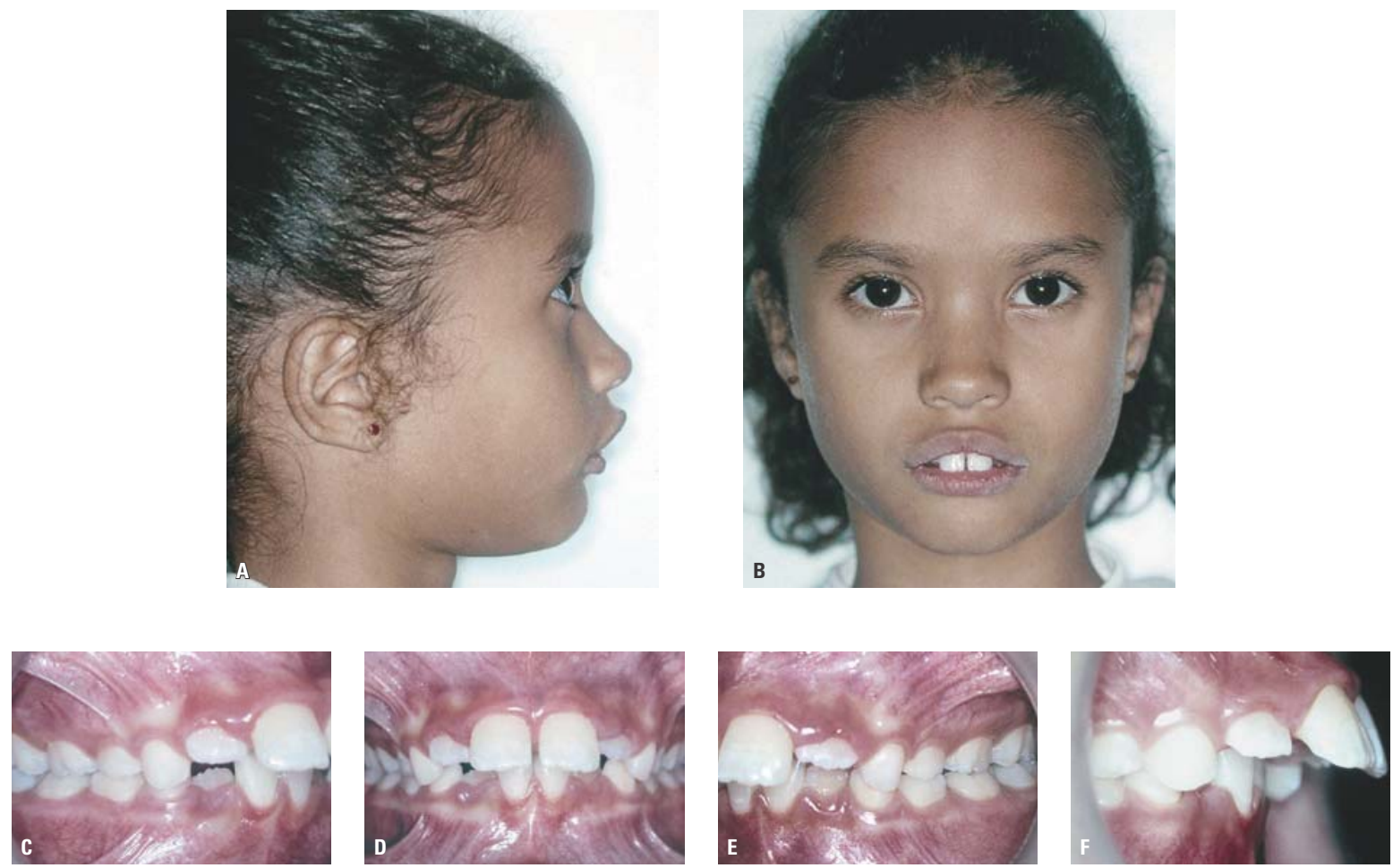

FIGURA 38 - Fotografias obtidas ao início do tratamento: A, B) faciais; C, D, E) intrabucais em oclusão; F) trespasse horizontal e vertical. 
licóides fornecem ao desenho original uma ação de força mais leve e contínua, para que possa ser utilizado na retração dos incisivos. Esta retração é realizada, principalmente, nos casos de extração, quando o espaço é criado na distal dos incisivos laterais pela distalização dos caninos, e em casos de Classe II, $1^{\text {a }}$ divisão.

Existem, ainda, algumas modificações do arco utilidade de retração, mas que não fogem muito do desenho original. Uma delas é a remoção de duas alças da extremidade gengival do degrau vertical posterior para a diminuição do componente extrusivo, como sugere Nobuyasu (apud FIGUEIREDO $^{8}$, 2000). Outra modificação consiste na adição de mais dois helicóides na região anterior da ponte lateral, como sugere Yokoyama ${ }^{31}$, e pode
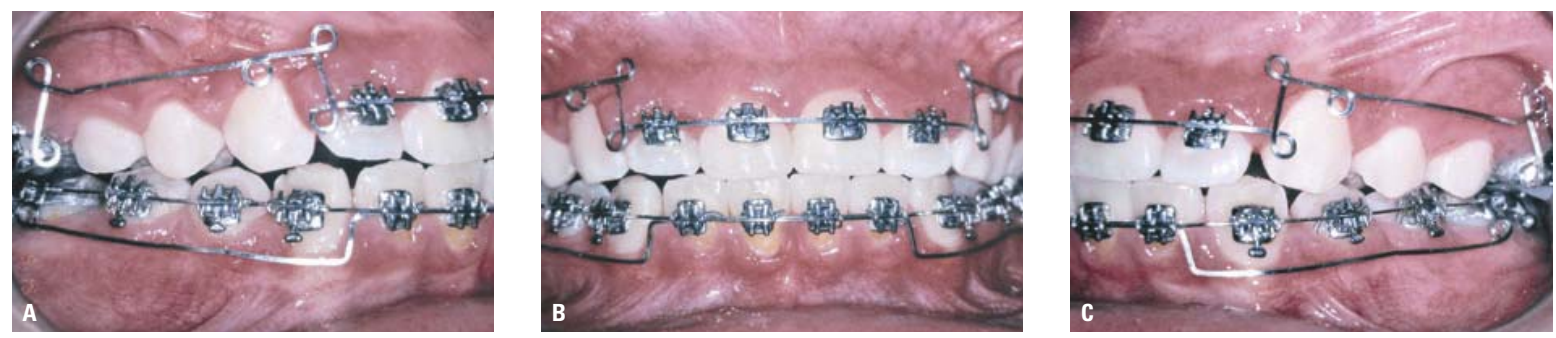

FIGURA 39 - Arco utilidade de retração, modificado por Moysés Yokoyama ${ }^{31}$ por meio da adição de mais 2 helicóides na porção anterior da ponte lateral, com 0 objetivo de manter uma ação de torque ainda mais efetiva.
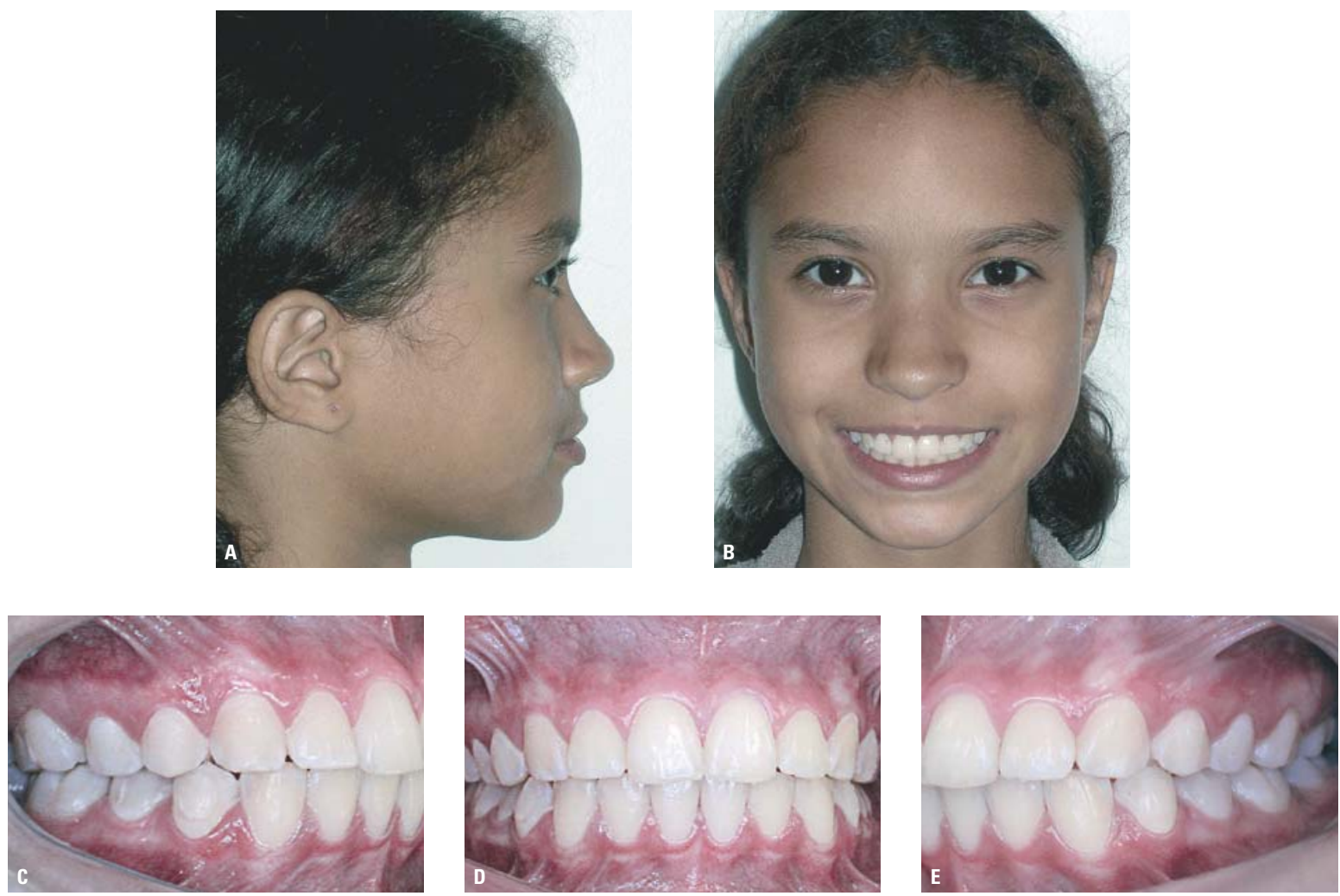

FIGURA 40 - Fotografias obtidas ao final do tratamento. 
ser observado por meio do caso clínico descrito nas figuras 38, 39 e 40 .

Segundo McNamara Jr. ${ }^{15}$, o arco utilidade de retração pode ser utilizado para fechar espaços interproximais enquanto intrui, alinha e corrige desvios de linha mediana.

\section{Arco utilidade de avanço}

Quando os incisivos inferiores necessitam de avanço, é necessário modificar o arco utilidade por meio de quatro ômegas inseridos na ponte lateral, próximos à região dos caninos (Fig. 41), ou quatro helicóides confeccionados nos cantos do arco utilidade ${ }^{8}$.
O degrau vertical posterior deve ficar justaposto ao tubo molar e a secção anterior permanecer 2 ou $3 \mathrm{~mm}$ à frente dos braquetes dos incisivos, antes de ser amarrada para o avanço (Fig. 42).

Estes ômegas fornecem ao arco utilidade uma maior flexibilidade e permitem o avanço de maneira controlada, com maior movimento de coroa ou de raiz. Para o arco utilidade superior, quando o objetivo for o maior movimento de raiz, a ativação deve ser realizada no ômega inferior, e quando o objetivo for o maior movimento de coroa a ativação deve ser feita no ômega superior ${ }^{19}$. O efeito deste arco utilidade de avanço pode ser observado nas figuras 43 a 46.

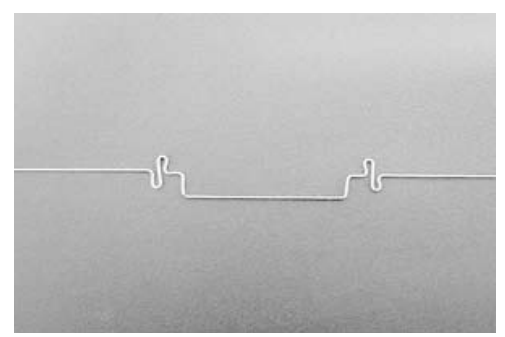

FIGURA 41 - Arco utilidade de avanço dos incisivos.

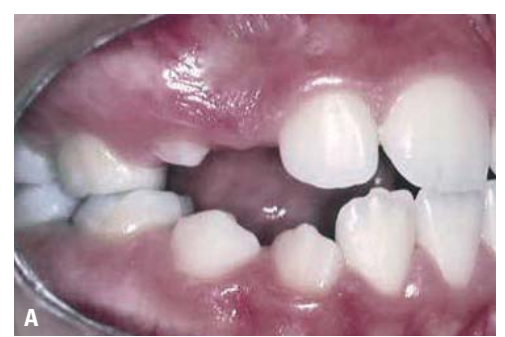

FIGURA 43 - Vistas intrabucais de uma paciente no final da dentadura mista.

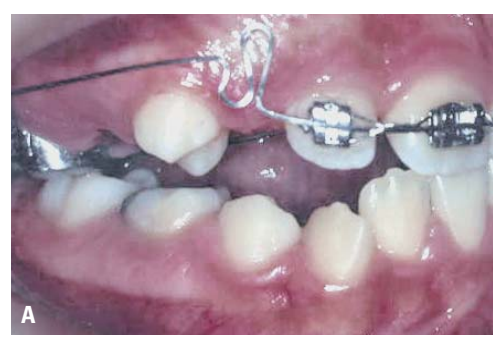

FIGURA 44 - Instalação do arco de avanço.
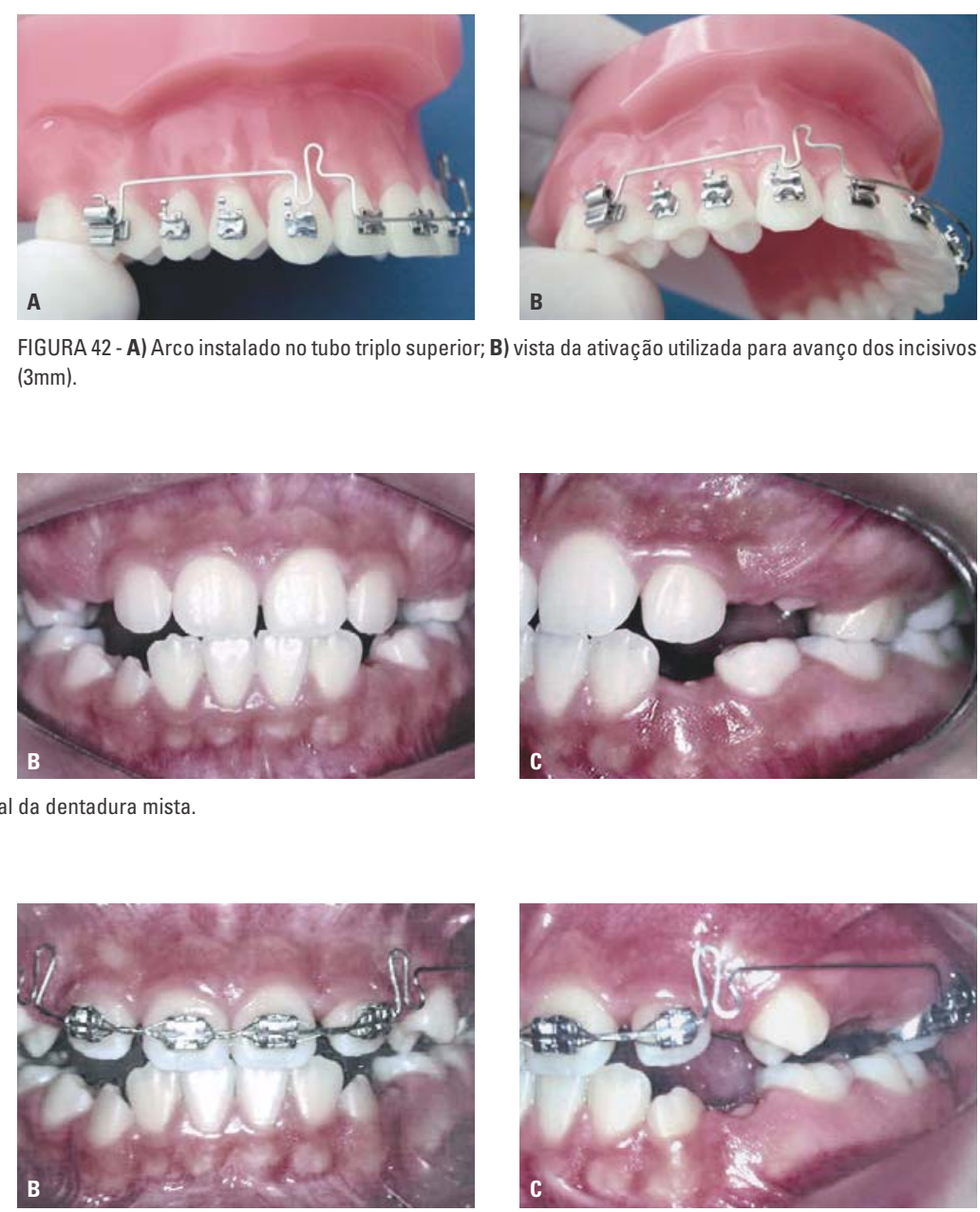

FIGURA 42 - A) Arco instalado no tubo triplo superior; B) vista da ativação utilizada para avanço dos incisivos (3mm).
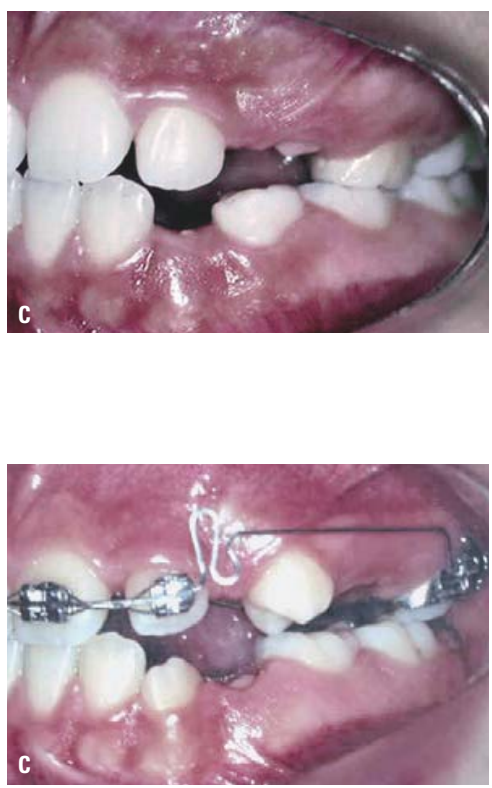

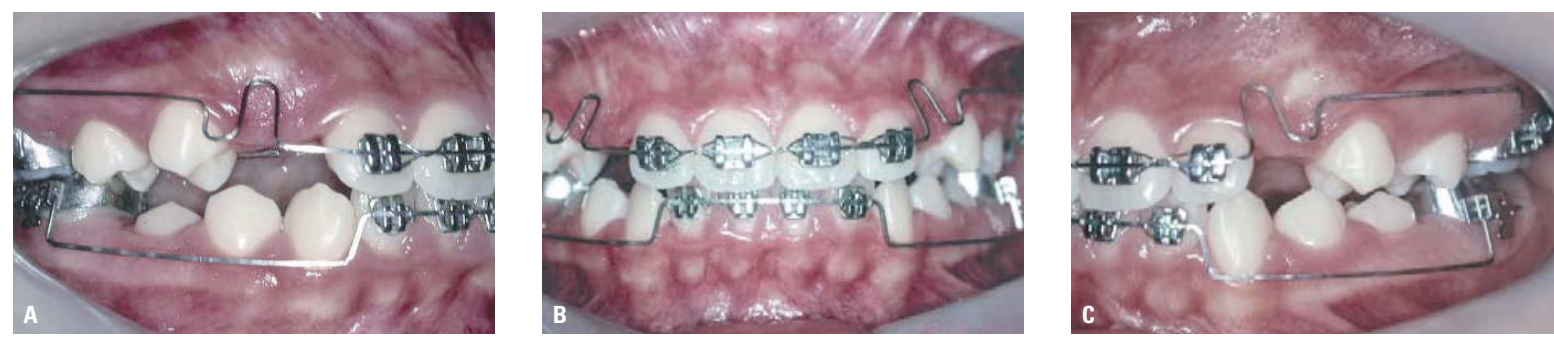

FIGURA 45 - Fotografias intrabucais obtidas durante o avanço dos incisivos. Pode-se observar a melhora do trespasse vertical e horizontal, assim como um excelente controle de torque dos incisivos superiores.
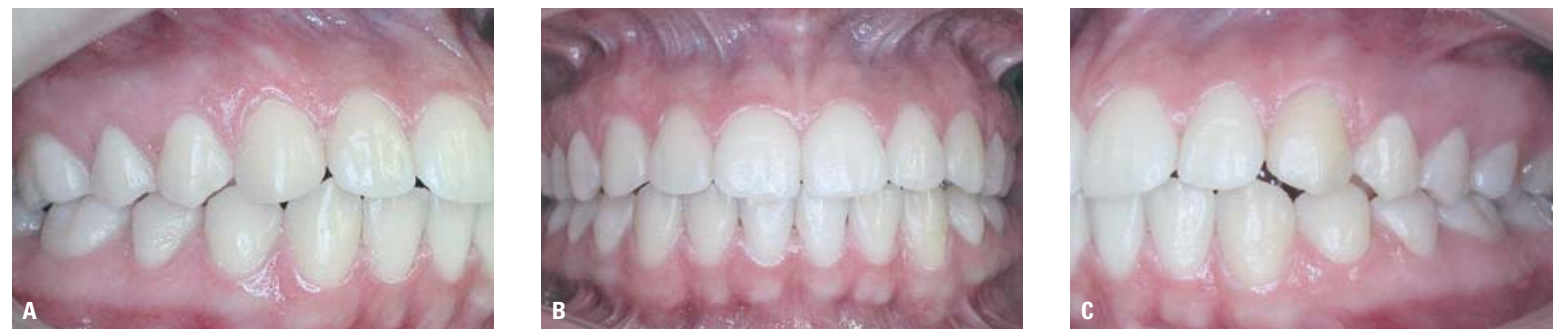

FIGURA 46 - Fotografias intrabucais obtidas ao final do tratamento. Trespasse vertical e horizontal corrigido. Pode-se observar falta de intercuspidação do dente 23 , portanto um esporão foi colocado por palatino para evitar que a língua se posicione no espaço e impeça a intercuspidação natural.

\section{RELATO DE CASO CLÍNICO}

Paciente M. R. L. A. do gênero masculino, 16 anos de idade, apresentava queixa de limitação de abertura de boca, de que os dentes estavam "descendo" e de barulho do lado esquerdo do rosto, próximo ao ouvido. O exame clínico intrabucal demonstrou presença de uma má oclusão do tipo Classe II, $2^{\text {a }}$ divisão, com mordida profunda (Fig. 47).

A estética da dentição estava prejudicada por um sorriso gengival. A mandíbula estava desviada para o lado esquerdo do paciente, com conseqüente assimetria facial e desvio da linha média inferior, também para o mesmo lado (Fig. 48).

$\mathrm{O}$ paciente apresentava uma abertura limitada da boca $(4 \mathrm{~cm})$, com presença de estalido no lado esquerdo da articulação temporomandibular, tanto durante os movimentos de lateralidade direita como esquerda. Apresentava, ainda, uma mordida cruzada vestibular do lado direito, como se pode verificar por meio da fotografia intrabucal (Fig. 49) e pelos modelos de estudo (Fig. 50).

A análise cefalométrica de Ricketts (Fig. 51, Tab. 1) demonstrou uma convexidade moderada $(4 \mathrm{~mm})$ em razão de suave prognatismo maxilar, padrão facial do tipo braquifacial, com os incisivos
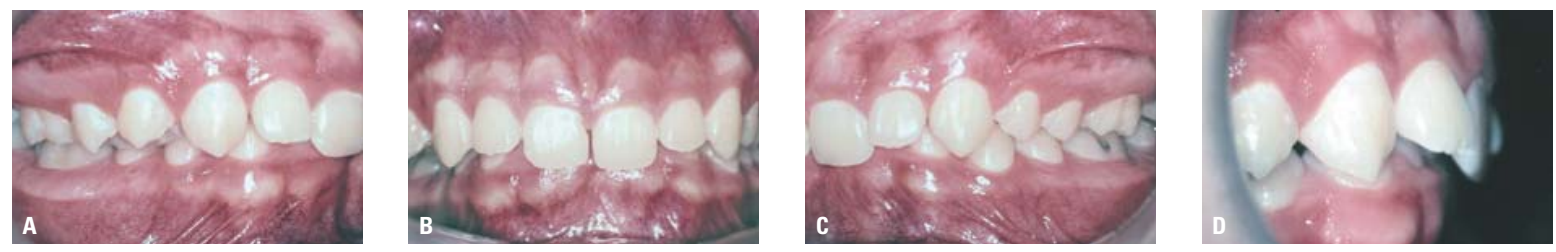

FIGURA 47 - Fotografias intrabucais obtidas no início do tratamento. 

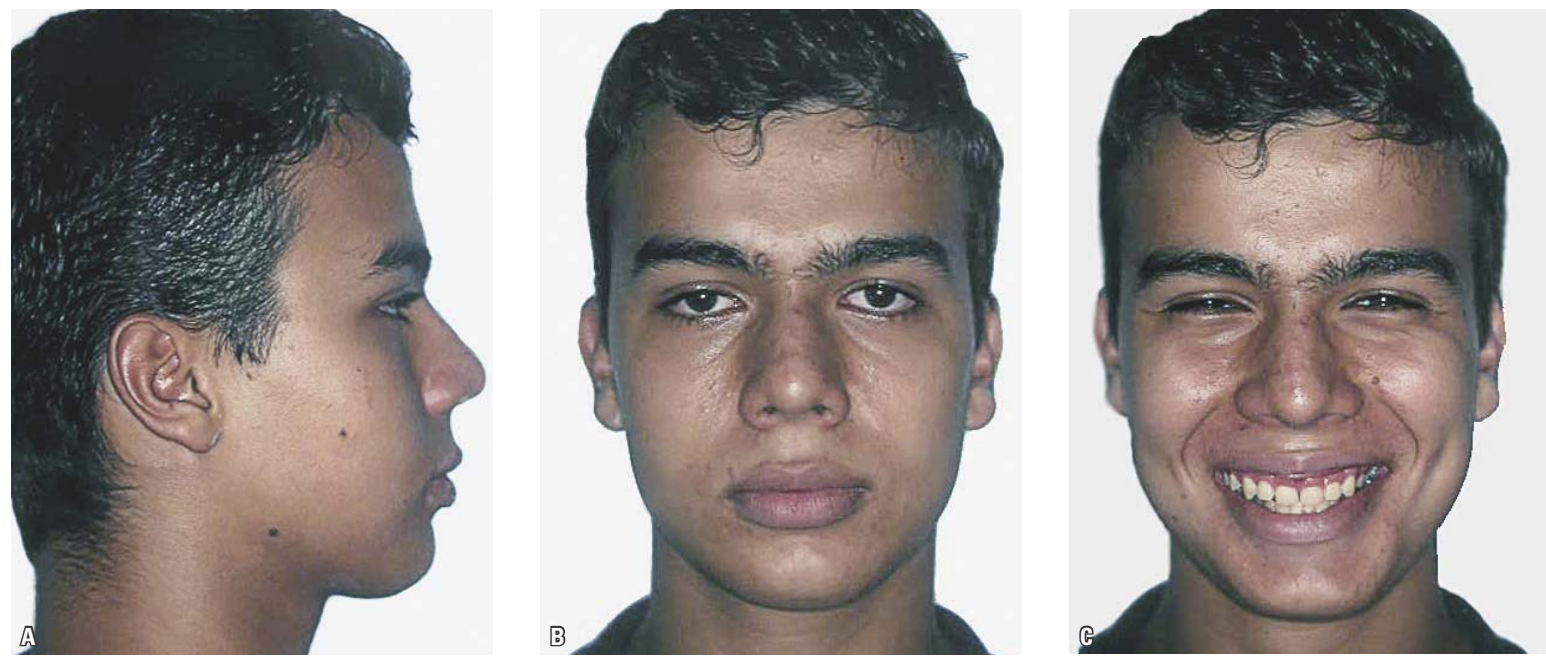

FIGURA 48 - Fotografias extrabucais obtidas ao início do tratamento.

superiores e inferiores verticalizados e extruídos, formando um ângulo interincisivos de $143^{\circ}$.

A análise de modelo inferior (Fig. 52), de acordo com Ricketts ${ }^{23,24}$, mostrou valores próximos dos normais para a dimensão transversal, porém a profundidade do arco estava próxima ao limite mínimo, considerando-se o desvio-padrão. Esta mensuração pode ajudar na avaliação do correto posicionamento dos incisivos inferiores. A medida indica um retroposicionamento dos incisivos quando apresenta-se diminuída, ou uma protrusão quando apresenta-se aumentada (Tab. 2).

\section{Plano de tratamento}

Duas alternativas de tratamento foram cogitadas, em razão da ausência de crescimento craniofacial. A primeira consistia em extrair os pri-

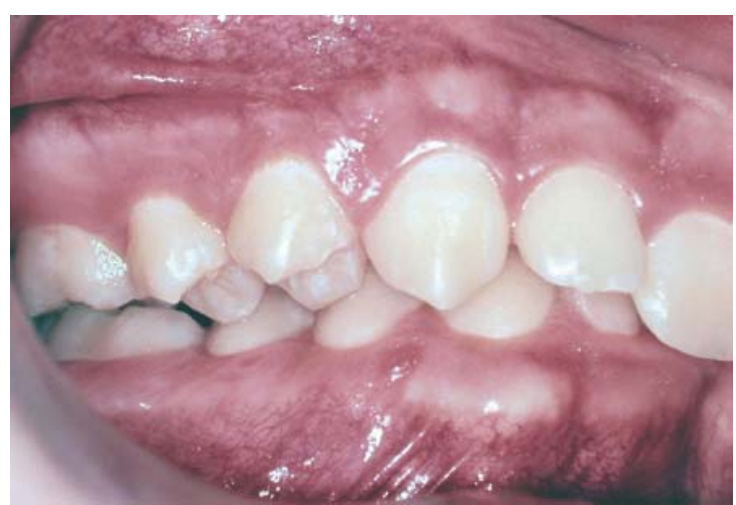

FIGURA 49 - Close-up da mordida cruzada vestibular.

meiros pré-molares superiores para correção do trespasse horizontal e posicionar os caninos em Classe I. A segunda opção seria corrigir a Classe II por meio de um movimento recíproco: dista-
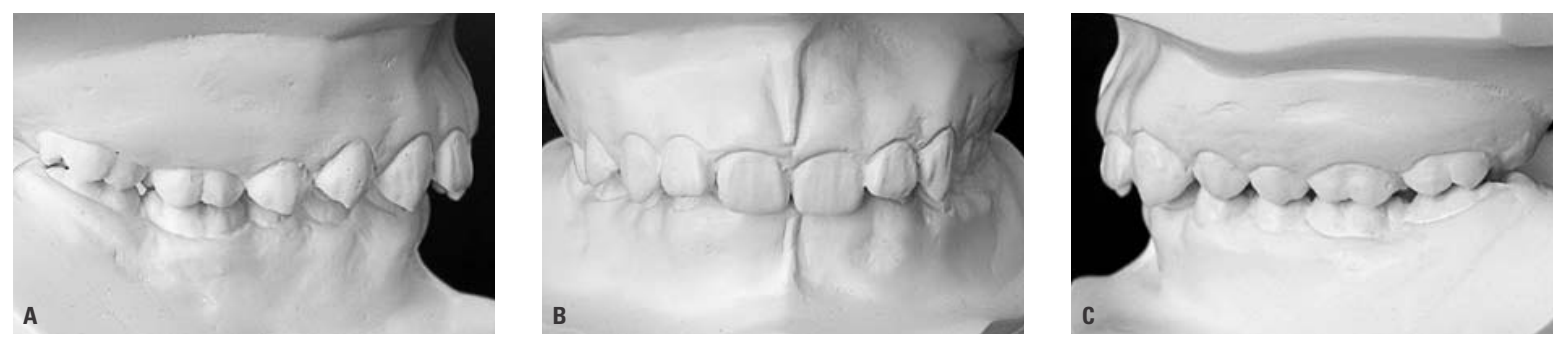

FIGURA 50 - Fotografias dos modelos de estudo iniciais. 

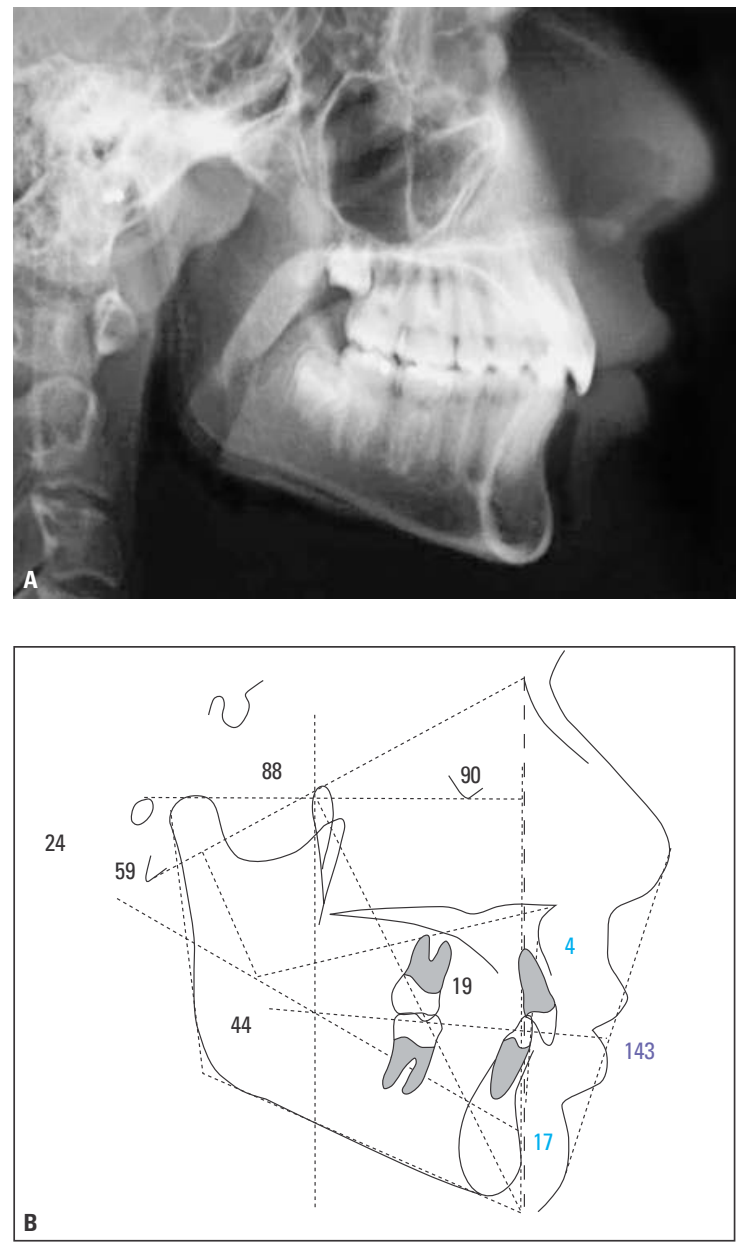

FIGURA 51 - A) Radiografia cefalométrica inicial; B) análise cefalométrica de Ricketts inicial.

lização dos dentes superiores e mesialização dos inferiores ${ }^{5}$. Segundo Uribe e Nanda ${ }^{30}$, pacientes com má oclusão do tipo Classe II, que apresentam discrepância esquelética moderada, podem receber tratamento compensatório. Os procedimentos comuns para estes pacientes incluem a redução interproximal dos dentes e extrações. A opção adotada, em comum acordo com o paciente e seu pai, foi realizar um tratamento sem extrações, em razão do padrão muscular do tipo braquifacial e da mordida profunda.

Os objetivos do tratamento foram corrigir a mordida cruzada invertida (vestibular) por meio do aparelho auxiliar do tipo bihélice, rotacionar
Tabela 1 - Valores iniciais com norma clínica e desvio-padrão para brasileiros ${ }^{18}$.

\begin{tabular}{|c|c|c|c|}
\hline & paciente & $\begin{array}{c}\text { valor } \\
\text { normal* }\end{array}$ & d.p.* \\
\hline \multicolumn{4}{|c|}{ relação dos dentes } \\
\hline relação molar & $-1 \mathrm{~mm}$ & $-2 \mathrm{~mm}$ & $1 \mathrm{~mm}$ \\
\hline relação dos caninos & $0 \mathrm{~mm}$ & $-1,5 \mathrm{~mm}$ & $0,5 \mathrm{~mm}$ \\
\hline trespasse horizontal & $7 \mathrm{~mm}$ & $3 \mathrm{~mm}$ & $0,5 \mathrm{~mm}$ \\
\hline trespasse vertical & $8 \mathrm{~mm}$ & $2,85 \mathrm{~mm}$ & $0,7 \mathrm{~mm}$ \\
\hline $\begin{array}{r}\text { extrusão do incisivo } \\
\text { inferior }\end{array}$ & $5 \mathrm{~mm}$ & $2 \mathrm{~mm}$ & $1 \mathrm{~mm}$ \\
\hline ângulo interincisivos & $143^{\circ}$ & $128^{\circ}$ & $5,6^{\circ}$ \\
\hline \multicolumn{4}{|c|}{ relação dos dentes com a base óssea } \\
\hline 6 Ptv & $19 \mathrm{~mm}$ & $18 \mathrm{~mm}$ & $3,5 \mathrm{~mm}$ \\
\hline $\begin{array}{l}\text { incisivo inferior } \\
\text { ao plano Apo }\end{array}$ & $-1 \mathrm{~mm}$ & $2 \mathrm{~mm}$ & $1,7 \mathrm{~mm}$ \\
\hline $\begin{array}{l}\text { inclinação do incisivo } \\
\text { inferior ao plano Apo }\end{array}$ & $17^{\circ}$ & $24,09^{\circ}$ & $3,2^{\circ}$ \\
\hline $\begin{array}{l}\text { incisivo superior } \\
\text { ao plano Apo }\end{array}$ & $6 \mathrm{~mm}$ & $5 \mathrm{~mm}$ & $1,9 \mathrm{~mm}$ \\
\hline $\begin{array}{l}\text { inclinação do incisivo } \\
\text { superior ao plano Apo }\end{array}$ & $20^{\circ}$ & $28^{\circ}$ & $5^{0}$ \\
\hline $\begin{array}{r}\text { plano oclusal ao } \\
\text { ponto Xi }\end{array}$ & $-7 \mathrm{~mm}$ & $-0,1 \mathrm{~mm}$ & $8,6 \mathrm{~mm}$ \\
\hline \multicolumn{4}{|c|}{ relação estética } \\
\hline $\begin{array}{r}\text { lábio inferior ao plano } \\
\text { estético }\end{array}$ & $2 \mathrm{~mm}$ & $-1 \mathrm{~mm}$ & $2,3 \mathrm{~mm}$ \\
\hline \multicolumn{4}{|c|}{ relação esqueletal } \\
\hline convexidade & $4 \mathrm{~mm}$ & $2 \mathrm{~mm}$ & $2 \mathrm{~mm}$ \\
\hline altura facial inferior & $44^{\circ}$ & $42^{\circ}$ & $2,6^{\circ}$ \\
\hline profundidade facial & $90^{\circ}$ & $89^{\circ}$ & $3^{0}$ \\
\hline eixo facial & $88^{\circ}$ & $93^{\circ}$ & $3^{0}$ \\
\hline profundidade maxilar & $93^{\circ}$ & $91^{\circ}$ & $3^{0}$ \\
\hline altura maxilar & $62^{\circ}$ & $56^{\circ}$ & $3,5^{\circ}$ \\
\hline $\begin{array}{l}\text { ângulo do plano } \\
\text { mandibular }\end{array}$ & $24^{\circ}$ & $23^{\circ}$ & $3^{0}$ \\
\hline altura facial total & $59^{\circ}$ & $55^{\circ}$ & $4^{0}$ \\
\hline \multicolumn{4}{|c|}{ estruturas internas } \\
\hline deflexão craniana & $29^{\circ}$ & $26^{\circ}$ & $2,7^{\circ}$ \\
\hline $\begin{array}{r}\text { comprimento craniano } \\
\text { anterior }\end{array}$ & $62 \mathrm{~mm}$ & $60 \mathrm{~mm}$ & $4 \mathrm{~mm}$ \\
\hline $\begin{array}{l}\text { altura do ramo } \\
\text { mandibular }\end{array}$ & $77 \mathrm{~mm}$ & $66 \mathrm{~mm}$ & $5,5 \mathrm{~mm}$ \\
\hline posição do ramo & $72^{\circ}$ & $73^{\circ}$ & $3^{0}$ \\
\hline pório-Ptv & $-44 \mathrm{~mm}$ & $-43 \mathrm{~mm}$ & $3 \mathrm{~mm}$ \\
\hline $\begin{array}{r}\text { comprimento do corpo } \\
\text { mandibular }\end{array}$ & $80 \mathrm{~mm}$ & $74 \mathrm{~mm}$ & $4 \mathrm{~mm}$ \\
\hline arco mandibular & $37^{\circ}$ & $32^{\circ}$ & $3,7^{\circ}$ \\
\hline padrão facial & & oraquifacia & \\
\hline
\end{tabular}

* os valores normais e desvio-padrão foram arredondados para facilitar a interpretação clínica. 


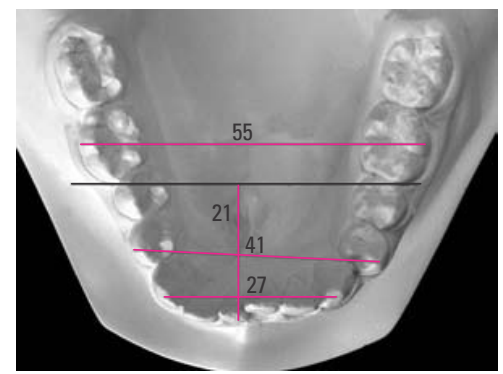

FIGURA 52 - Vista oclusal do modelo inferior inicial.
Tabela 2 - Análise de modelos de acordo com Ricketts ${ }^{23,24}$.

\begin{tabular}{ccc} 
mandíbula & medida & norma e d.p. \\
\hline profundidade do arco & $21 \mathrm{~mm}$ & $22,2 \pm 1,4 \mathrm{~mm}$ \\
distância intermolares & $55 \mathrm{~mm}$ & $54,2 \pm 2,4 \mathrm{~mm}$ \\
distância inter pré-molares & $41 \mathrm{~mm}$ & $39,8 \pm 2,0 \mathrm{~mm}$ \\
distância intercaninos & $27 \mathrm{~mm}$ & $25,3 \pm 1,6 \mathrm{~mm}$ \\
\hline
\end{tabular}
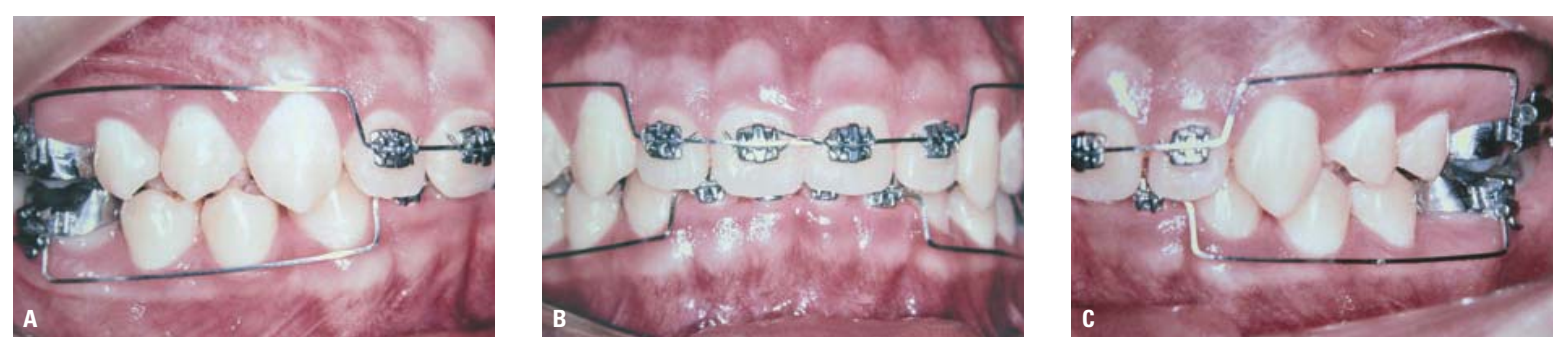

FIGURA 53 - Fotografias intrabucais obtidas durante o tratamento, mostrando 0 arco utilidade superior e inferior.
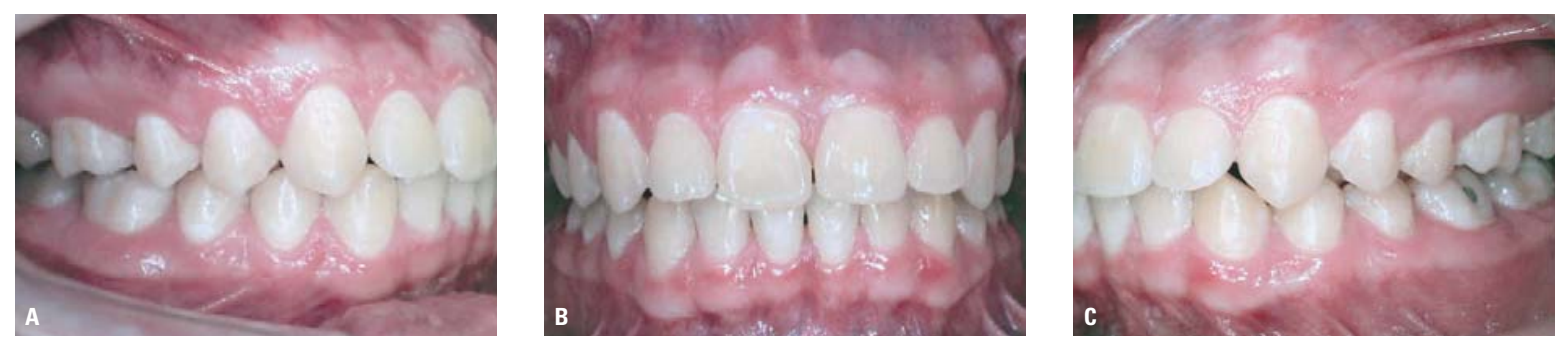

FIGURA 54 - Fotografias intrabucais obtidas ao final do tratamento.

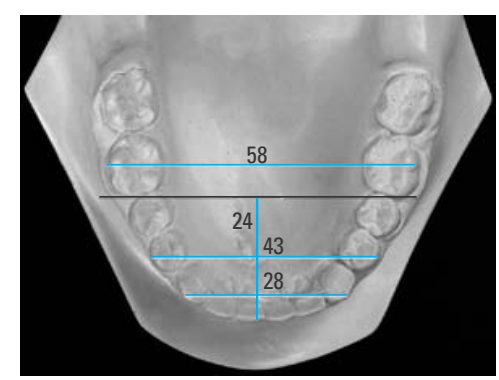

Tabela 3 - Análise do modelo inferior pós-tratamento.

FIGURA 55 - Vista oclusal do modelo inferior final.

\begin{tabular}{rcc}
\hline mandíbula & medida & norma e d.p. \\
\hline profundidade do arco & $24 \mathrm{~mm}$ & $22,2 \pm 1,4 \mathrm{~mm}$ \\
distância intermolares & $58 \mathrm{~mm}$ & $54,2 \pm 2,4 \mathrm{~mm}$ \\
distância inter pré-molares & $43 \mathrm{~mm}$ & $39,8 \pm 2,0 \mathrm{~mm}$ \\
distância intercaninos & $28 \mathrm{~mm}$ & $25,3 \pm 1,6 \mathrm{~mm}$ \\
\hline
\end{tabular}



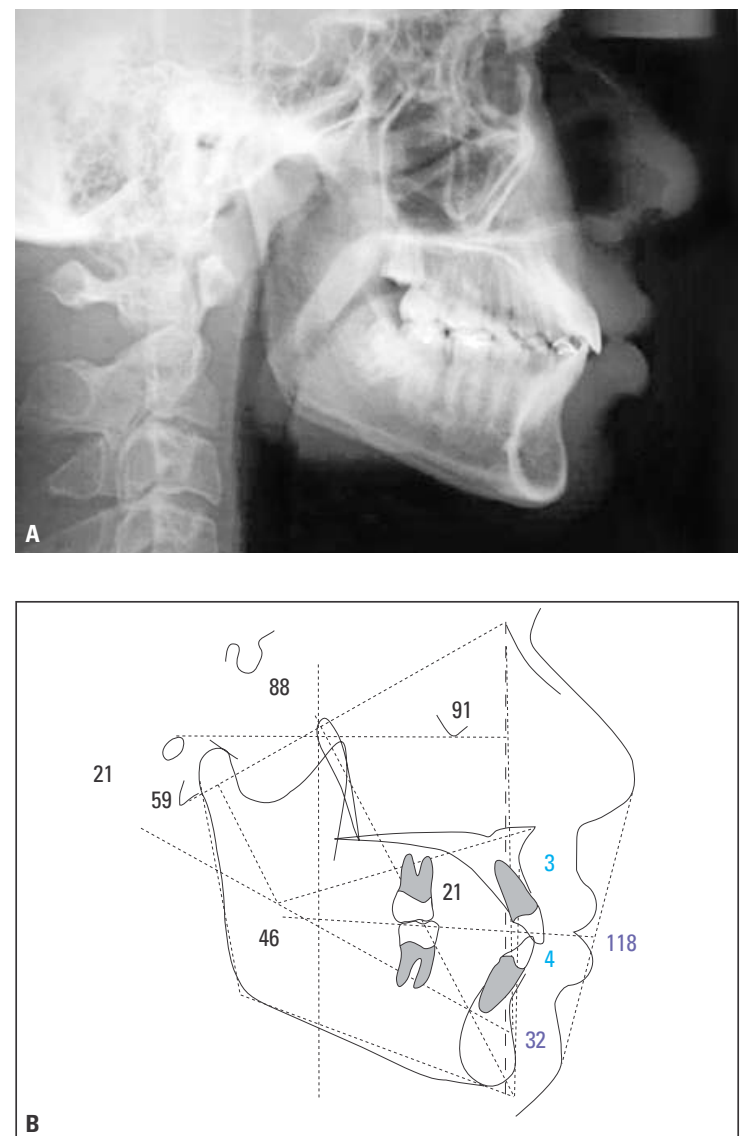

FIGURA 56 - A) Radiografia cefalométrica final; B) análise cefalométrica de Ricketts final.

os primeiros molares superiores com o aparelho auxiliar quadrihélice, intruir os incisivos superiores e inferiores por meio do arco utilidade (Fig. 53) e correção da má oclusão Classe II por meio de mecânica de elásticos intermaxilares com direção de Classe II, utilizados com a mecânica seccionada de Ricketts ${ }^{3}$.

As fotografias intrabucais do final do tratamento (Fig. 54) demonstram que os objetivos do tratamento foram atingidos: correção da Classe II, da mordida profunda e da mordida cruzada vestibular.

Pode-se observar, por meio da análise dos modelos finais (Fig. 55, Tab. 3), que houve uma
Tabela 4 - Valores cefalométricos finais com norma clínica e desvio-padrão para brasileiros ${ }^{18}$.

\begin{tabular}{|c|c|c|c|}
\hline & paciente & $\begin{array}{c}\text { valor } \\
\text { normal* }\end{array}$ & d.p.* \\
\hline \multicolumn{4}{|c|}{ relação dentária } \\
\hline relação molar & $-3 m m$ & $-2 \mathrm{~mm}$ & $1 \mathrm{~mm}$ \\
\hline relação dos caninos & $-2 m m$ & $-1,5 \mathrm{~mm}$ & $0,5 \mathrm{~mm}$ \\
\hline trespasse horizontal & $3 \mathrm{~mm}$ & $3 \mathrm{~mm}$ & $0,5 \mathrm{~mm}$ \\
\hline trespasse vertical & $2 \mathrm{~mm}$ & $2,85 \mathrm{~mm}$ & $0,7 \mathrm{~mm}$ \\
\hline extrusão do incisivo inferior & $-1 \mathrm{~mm}$ & $2 \mathrm{~mm}$ & $1 \mathrm{~mm}$ \\
\hline ângulo interincisivos & $118^{\circ}$ & $128^{\circ}$ & $5,6^{\circ}$ \\
\hline \multicolumn{4}{|c|}{ dentes com relação à base óssea } \\
\hline 6 Ptv & $21 \mathrm{~mm}$ & $18 \mathrm{~mm}$ & $3,5 \mathrm{~mm}$ \\
\hline $\begin{array}{l}\text { incisivo inferior } \\
\text { ao plano Apo }\end{array}$ & $4 \mathrm{~mm}$ & $2 \mathrm{~mm}$ & $1,7 \mathrm{~mm}$ \\
\hline $\begin{array}{l}\text { inclinação do incisivo infe- } \\
\text { rior ao plano Apo }\end{array}$ & $32^{\circ}$ & $24,09^{\circ}$ & $3,2^{\circ}$ \\
\hline $\begin{array}{l}\text { incisivo superior } \\
\text { ao plano Apo }\end{array}$ & $7 \mathrm{~mm}$ & $5 \mathrm{~mm}$ & $1,9 \mathrm{~mm}$ \\
\hline $\begin{array}{l}\text { inclinação do incisivo } \\
\text { superior ao plano Apo }\end{array}$ & $30^{\circ}$ & $28^{\circ}$ & $5^{0}$ \\
\hline plano oclusal ao ponto $\mathrm{Xi}$ & $-4 m m$ & $-0,1 \mathrm{~mm}$ & $8,6 \mathrm{~mm}$ \\
\hline \multicolumn{4}{|c|}{ relação estética } \\
\hline $\begin{array}{l}\text { lábio inferior } \\
\text { ao plano estético }\end{array}$ & $1 \mathrm{~mm}$ & $-1 \mathrm{~mm}$ & $2,3 \mathrm{~mm}$ \\
\hline \multicolumn{4}{|c|}{ relação esqueletal } \\
\hline convexidade & $3 \mathrm{~mm}$ & $2 \mathrm{~mm}$ & $2 \mathrm{~mm}$ \\
\hline altura facial inferior & $44^{\circ}$ & $42^{\circ}$ & $2,6^{\circ}$ \\
\hline profundidade facial & $91^{\circ}$ & $89^{\circ}$ & $3^{0}$ \\
\hline eixo facial & $88^{\circ}$ & $93^{\circ}$ & $3^{\circ}$ \\
\hline profundidade maxilar & $94^{\circ}$ & $91^{\circ}$ & $3^{\circ}$ \\
\hline altura maxilar & $62^{\circ}$ & $56^{\circ}$ & $3,5^{\circ}$ \\
\hline ângulo do plano mandibular & $21^{\circ}$ & $23^{\circ}$ & $3^{0}$ \\
\hline altura facial total & $59^{\circ}$ & $55^{\circ}$ & $4^{0}$ \\
\hline \multicolumn{4}{|c|}{ estruturas internas } \\
\hline deflexão craniana & $30^{\circ}$ & $26^{\circ}$ & $2,7^{\circ}$ \\
\hline $\begin{array}{r}\text { comprimento craniano } \\
\text { anterior }\end{array}$ & $62 \mathrm{~mm}$ & $60 \mathrm{~mm}$ & $4 \mathrm{~mm}$ \\
\hline altura do ramo mandibular & $77 \mathrm{~mm}$ & $66 \mathrm{~mm}$ & $5,5 \mathrm{~mm}$ \\
\hline posição do ramo & $76^{\circ}$ & $73^{\circ}$ & $3^{\circ}$ \\
\hline pório-Ptv & $-40 \mathrm{~mm}$ & $-43 \mathrm{~mm}$ & $3 \mathrm{~mm}$ \\
\hline $\begin{array}{r}\text { comprimento do corpo } \\
\text { mandibular }\end{array}$ & $81 \mathrm{~mm}$ & $74 \mathrm{~mm}$ & $4 \mathrm{~mm}$ \\
\hline arco mandibular & $34^{\circ}$ & $32^{\circ}$ & $3,7^{\circ}$ \\
\hline padrão facial & & raquifacial & \\
\hline
\end{tabular}

* os valores normais e desvio-padrão foram arredondados para facilitar a interpretação clínica. 
expansão dentoalveolar no arco mandibular, que colaborou para a correção da mordida cruzada invertida e aumento da profundidade do arco, o que demonstrou que os incisivos inferiores foram avançados.

A análise cefalométrica final (Fig. 56, Tab. 4) confirmou o avanço dos incisivos inferiores, com o valor de 1-APo passando de $-1 \mathrm{~mm}$ para $4 \mathrm{~mm}$, e da convexidade diminuindo $1 \mathrm{~mm}$, melhorando o perfil facial do paciente. Esta mudança foi devida ao movimento de angulação lingual (torque) de raiz nos incisivos superiores implementado pelo tratamento, que teve como objetivo tornar esta inclinação paralela com o eixo facial de Ricketts. Segundo Langlade ${ }^{14}$, a angulação dos incisivos superiores paralela ao eixo facial apresenta maior estabilidade na correção da mordida profunda.

Esta modificação do posicionamento dos incisivos superiores, associada ao avanço dos incisivos inferiores, fez com que o ângulo interincisivos diminuísse de $143^{\circ}$, no início do tratamento, para $118^{\circ}$, ao final. O restante das medidas não apresentou grandes modificações, em razão da ausência de crescimento craniofacial entre o início e final do tratamento.

Pode-se observar, por meio da análise de sobreposições cefalométricas de Ricketts (apud FIGUEIREDO et al. ${ }^{9}$, 2005), nas figuras 57A e 57B, que não houve crescimento na mandíbula, nem na maxila (áreas de avaliação 1 e 2). O deslocamento
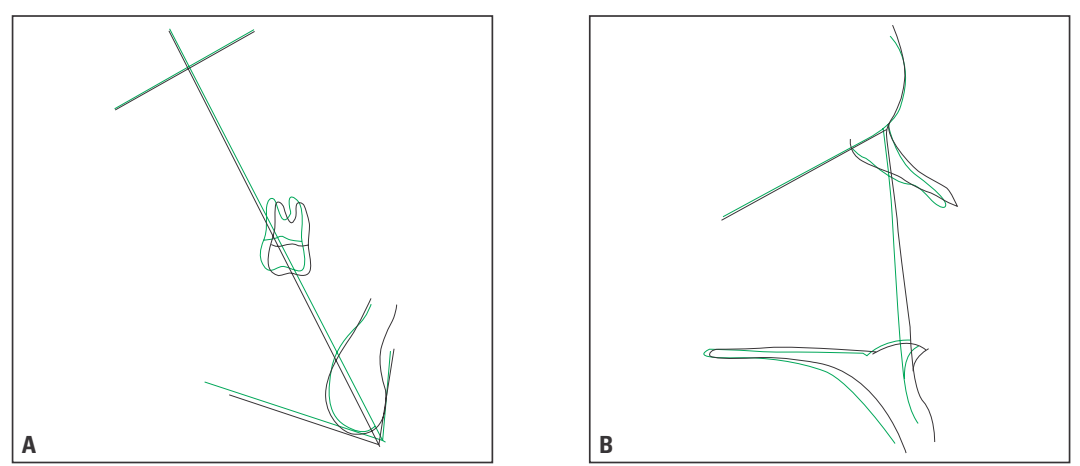

FIGURA 57 - Sobreposição cefalométrica inicial (preto) e final (verde): A) não houve modificação no posicionamento espacial da mandíbula durante o tratamento; B) o ponto $A$ (referência da maxila) foi retraído, em decorrência do torque lingual de raiz nos incisivos superiores.
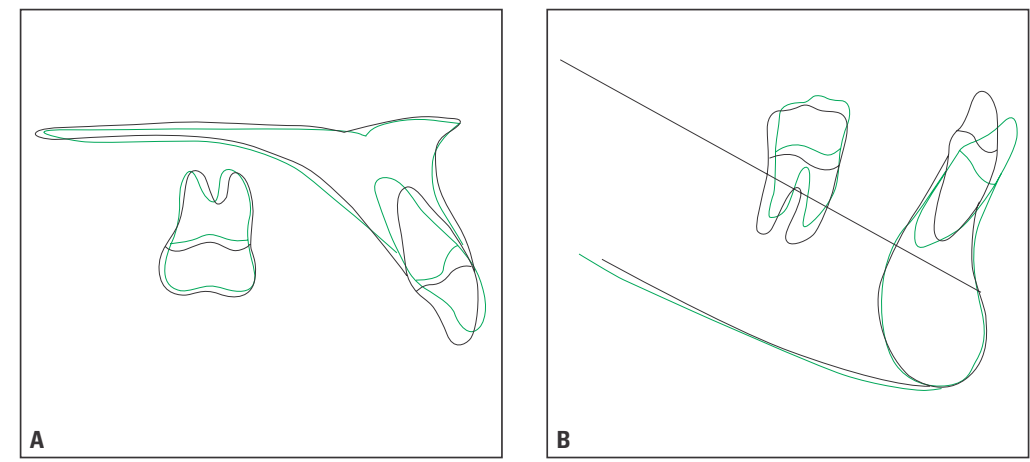

FIGURA 58 - Sobreposição cefalométrica inicial (preto) e final (verde): A) incisivos superiores tiveram sua angulação modificada (torque lingual de raiz) e foram intruídos, já os molares só foram intruídos; B) os incisivos inferiores foram avançados e intruídos e os molares mesializaram $2 \mathrm{~mm}$, verticalizaram e extruíram.

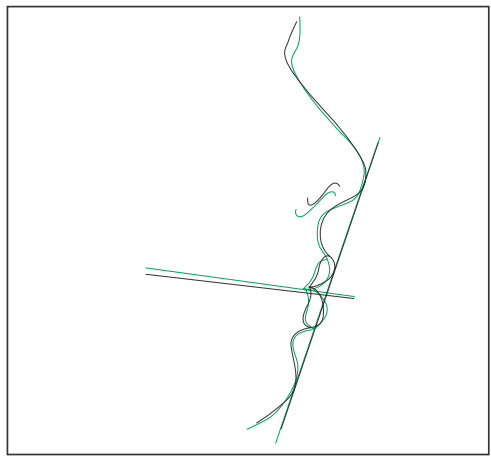

FIGURA 59 - A sobreposição inicial (preto) e final (verde) mostra um avanço do lábio inferior e uma retrusão do lábio superior. 
distal do ponto "A" ocorreu por conta da inclinação lingual de raiz dos incisivos superiores (efeito da mecânica ortodôntica).

Por outro lado, as áreas de avaliação 3 e 4 demonstram alteração no posicionamento dos incisivos superiores e inferiores, pois foram intruídos, inclinados para a vestibular e avançados. Os molares superiores foram bloqueados, não mudando o seu posicionamento desde o início até o final do tratamento, pois o desenvolvimento sem trata- mento levaria estes dentes $0,6 \mathrm{~mm}$ para a frente. Os molares inferiores mesializaram $2 \mathrm{~mm}$ e também extruíram $2 \mathrm{~mm}$, como pode-se observar nas figuras $58 \mathrm{~A}$ e $58 \mathrm{~B}$.

A quinta área de avaliação apresentou pouca alteração, podendo ser observado um crescimento do nariz e uma retrusão do lábio superior, o que colaborou para a melhora da aparência facial do paciente (Fig. 59).

As fotografias extrabucais e intrabucais de 5
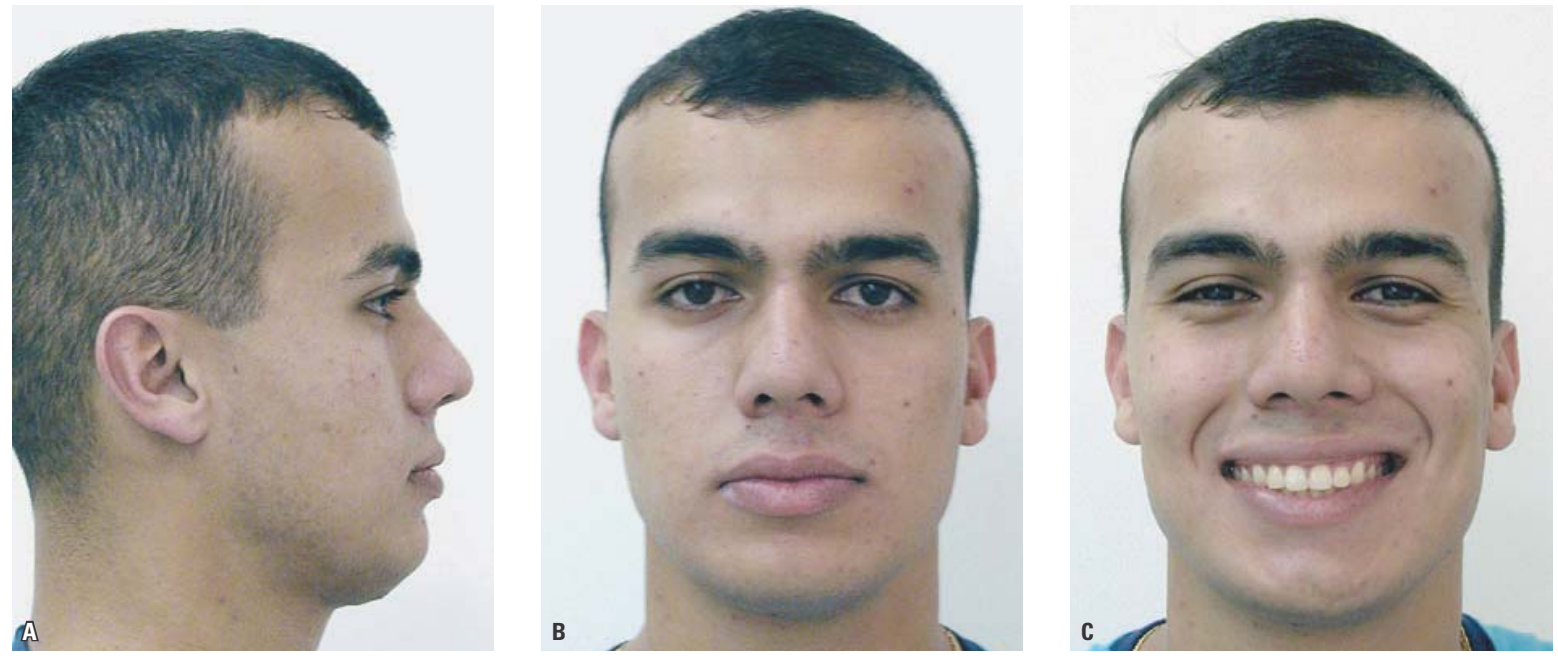

FIGURA 60 - Fotografias extrabucais obtidas 5 anos pós-tratamento.
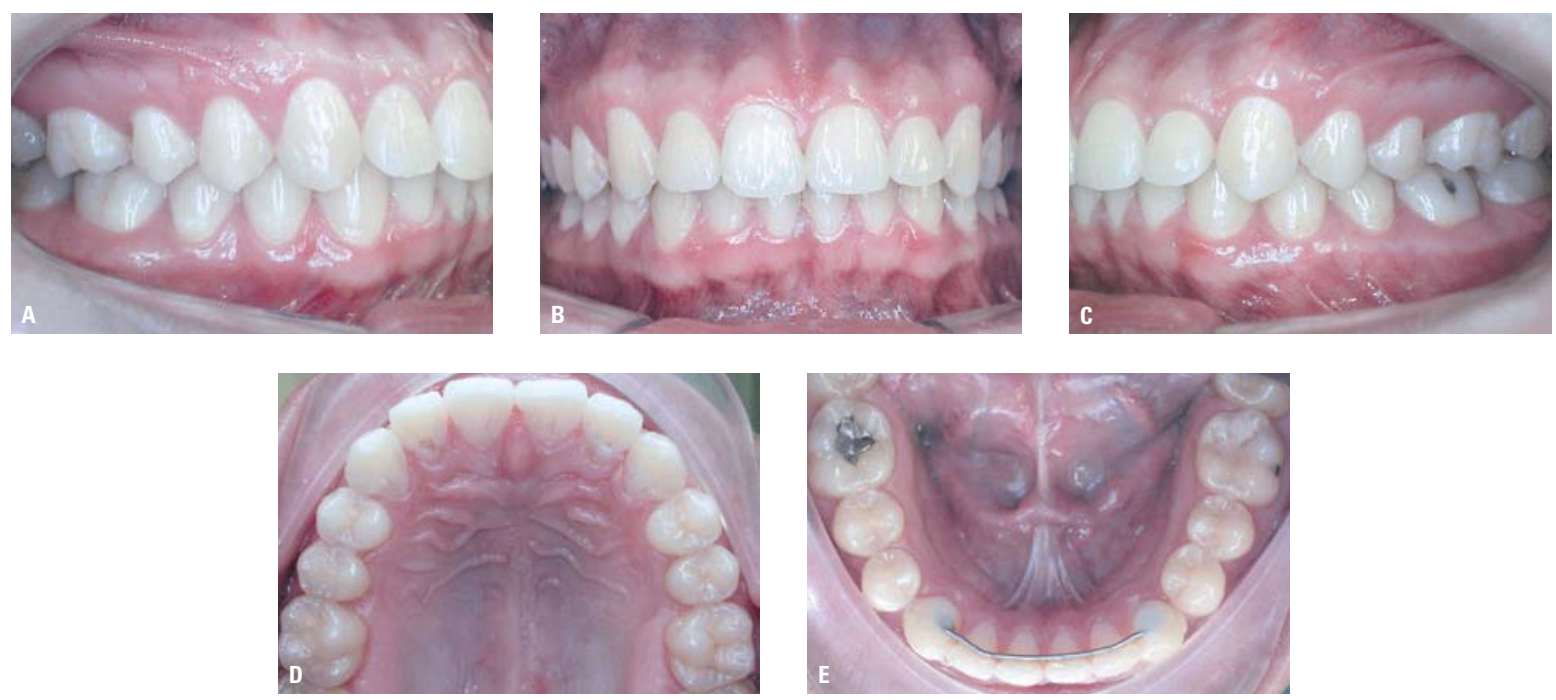

FIGURA 61 - Fotografias intrabucais obtidas 5 anos pós-tratamento. 

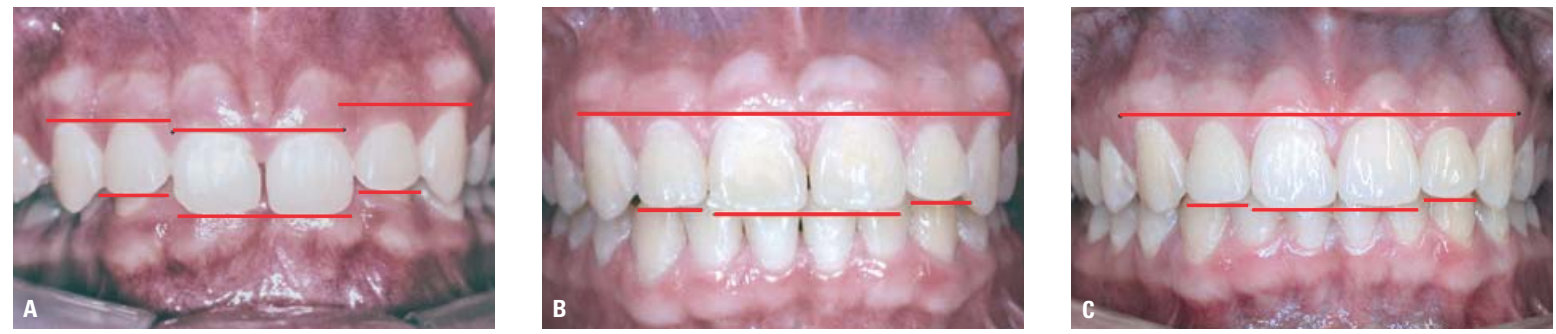

FIGURA 62 - Fotografias intrabucais: A) início do tratamento; B) final do tratamento; C) 5 anos após o final do tratamento.

anos pós-tratamento ortodôntico (Fig. 60, 61) demonstram estabilidade dos resultados obtidos, função adequada e uma excelente estética do sorriso e da face.

Por fim, as fotografias intrabucais do início do tratamento, final e 5 anos pós-tratamento (Fig. 62) mostram a melhora obtida nos limites cervicais das coroas clínicas dos incisivos superiores e do contorno gengival, além da correção e da estabilidade da mordida profunda.

\section{CONSIDERAÇÕES FINAIS}

$\mathrm{O}$ arco utilidade é um aparelho extremamente versátil, com inúmeras possibilidades clínicas, sendo capaz de intruir, extruir, avançar ou retrair os incisivos superiores e inferiores; manter, diminuir ou aumentar o espaço no arco inferior; além de ancorar os molares inferiores. Entretanto, uma das maiores vantagens de seu uso consiste na correção de más oclusões do tipo Classe II, com mordida profunda e em fase de crescimento. Esta vantagem não está relacionada com o efeito mecânico de intrusão, mas com a resposta biológica que esta mecânica pode acarretar no crescimento facial.

\section{AGRADECIMENTOS}

Agradecemos à empresa MEDSIMULATOR, criadora do software Ortovisual 2, e, em especial, aos amigos Henrique Nossar, Alexandre Alves e Viviane Maia pela valiosa colaboração com as ilustrações utilizadas neste artigo.

Enviado em: julho de 2007 Revisado e aceito: janeiro de 2008

\title{
The clinical versatility of the utility archwire
}

\begin{abstract}
Introduction: The utility archwire, along with the quad-helix, is the most widely known and used device within the Bioprogressive technique for the treatment of several malocclusions. Featuring a simple yet original design, the utility archwire has become an integral part of the orthodontic arsenal, with applications in the periods of mixed and permanent dentition. The name of this archwire refers to its great versatility, and to the multiple effects it can have during treatment. Objective: This article aims to discuss the production, application and clinical use of the Ricketts utility archwire in orthodontic treatments, as well as to describe some of the basics aspects of the Bioprogressive orthodontic technique. Conclusion: It can be concluded that the utility archwire is an extremely versatile appliance with innumerable clinical applications - able to intrude, extrude, advance or retract maxillary or mandibular incisors; maintain, diminish or increase space in the lower arch, in addition to anchoring mandibular molars. Nevertheless, one of the most significant advantages of its use is in the correction of Class II malocclusions, with overbite.
\end{abstract}

Key words: Bioprogressive. Utility arch. Orthodontics. 


\section{REFERÊNCIAS}

1. BENCH, R. W.; GUGINO, C. F.; HILGERS, J. J. Bioprogressive therapy. Part 2: principles of the bioprogressive therapy. J. Clin. Orthod., Boulder, v. 11, p. 661-682, 1977.

2. BENCH, R. W.; GUGINO, C. F.; HILGERS, J. J. Bioprogressive therapy. Part 6: forces used in bioprogressive therapy. J. Clin. Orthod., Boulder, v. 12, p. 123-139, 1978

3. BENCH, R. W.; GUGINO, C. F.; HILGERS, J. J. Bioprogressive therapy. Part 7: the utility and sectional arches in bioprogressive therapy mechanics. J. Clin. Orthod., Boulder, v. 12, p. $192-207,1978$.

4. BENCH, R. W.; GUGINO, C. F.; HILGERS J. J. Bioprogressive therapy. Part 10: mechanics sequence for Class II Division 1 cases. J. Clin. Orthod., Boulder, v. 12, p. 427-439, 1978.

5. BENCH, R. W.; GUGINO, C. F.; HILGERS, J. J. Bioprogressive therapy. Part 11: mechanics sequence for Class II Division 2 cases. J. Clin. Orthod., Boulder, v. 12, p. 505-521, 1978.

6. COOK, A. H.; SELLKE, T. A.; BEGOLE, E. A. Control of the vertical dimension in Class II correction using a cervical headgear and lower utility arch in growing patients. Am. J. Orthod. Dentofacial Orthop., St. Louis, v. 106, no. 4, p. 376-388, 1994

7. ELLEN, E. K.; SCHNEIDER, B. J.; SELLKE, T. A comparative study of anchorage in bioprogressive versus standard edgewise treatment in Class II correction with intermaxillary elastic force. Am. J. Orthod. Dentofacial Orthop., St. Louis, v. 114 , no. 4, p. 430-436, 1998.

8. FIGUEIREDO, M. A. Manual para treinamento e préfabricação de arcos contínuos e seccionais em terapia bioprogressiva de Ricketts. [S. I.]: N \& F Ortho Dental, 2000. . FIGUEIREDO, M. A.; SIQUEIRA, D. F.; BOMMARITO, S.; SCANAVINI, M. A. Sobreposições cefalométricas de Ricketts. Rev. Dental Press Ortodon. Ortop. Facial, Maringá, v. 10, n. 3, p. 138-156, 2005.

10. GREGORE, T. J.; TUBER, E.; ESCOBAR, H. El tratamiento ortodóncico com arco recto. Madrid: NM Ediciones, 2003.

11. GIANELLY, A. A. Leeway space and the resolution of crowding in the mixed dentition. Semin. Orthod., Philadelphia, v. 1 , no. 3, p. 188-194, 1995.

12. GIANELLY, A. A. Treatment of crowding in the mixed dentition. Am. J. Orthod. Dentofacial Orthop., St. Louis, v. 121, no. 6 p. 569-571, 2002.

13. GURGEL, J. A.; RAMOS, A. L.; KERR, S. D. Fios ortodônticos. Rev. Dental Press Ortodon. Ortop. Facial, Maringá, v. 6, n. 4, p. 103-114, 2001

14. LANGLADE, M. Diagnóstico ortodôntico. São Paulo: Ed. Santos, 1993

15. McNAMARA JR., J. A. Utility arches. J. Clin. Orthod., Boulder, v. 20, p. $452-456,1986$

16. MCNAMARA JR., J. A. Ordinary Orthodontics: starting with the end in mind. World. J. Orthod., Carol Stream, v. 1, p. 45-54, 2000.
17. MIKSIC, M.; SLAJ, M.; MESTROVIC, S. Bioprogressive therapy and diagnostics. Acta Stomatol. Croat., Zagreb, v. 37, no. 4, p. 461-464, 2003

18. NOBUYASU, M.: MYAHARA, M.: TAKAHASHI, T.; ATTIZZANI, A.; MARUO, H.; RINO, W.; NOBUYASU, A. M.; CARVALHO, S M. R. Padrões cefalométricos de Ricketts aplicados a indivíduos brasileiros com oclusão excelente. Rev. Dental Press Ortodon. Ortop. Facial, Maringá, v. 12, n. 1, p. 125-156, 2007.

19. NOSSAR, H.; TURETA, V.; FIGUEIREDO, M. A. Software, Ortovisual 2: Medsimulator Informática. Teresópolis: [s.n.], 2006.

20. OTTO, R. L.; ANHOLM, J. M. N.; ENGEL, G. A. A comparative analysis of intrusion of incisor teeth achieved in adults and children according to facial type. Am. J. Orthod., St. Louis, v. 77, p. $437-446,1980$.

21. PRESTON, C. B.; KOZLOWSKI, J.; EVANS, B. Adaptation of the bioprogressive philosophy to use brackets with "022" slots. Semin. Orthod., Philadelphia, v. 4, p. 238-245, 1998.

22. RICKETTS, R. M. Bioprogressive therapy as an answer to orthodontic needs. Am. J. Orthod., St. Louis, v. 70, p. 241-268, 1976.

23. RICKETTS, R. M. Provocations and perceptions in craniofacial Orthopedics. Glendora: RMO, p. 735, 817-818, 1989.

24. RICKETTS, R. M. The wisdom of the bioprogressive philosophy. Semin. Orthod., Philadelphia, v. 4, p. 201-209, 1998

25. RICKETTS, R. M. A sabedoria da mecânica seccional: tração intermaxilar na terapia sem extração. Goiânia: Kelps, 1999.

26. RICKETTS, R. M. Conceitos de mecânica e biomecânica Goiânia: Artes Gráficas, 2003.

27. SELLKE, T. A. Zero base bioprogressive: unlocking the door to the future Semin. Orthod. Philadelphia, v. 4, p. 210-218, 1998.

28. ÜLGER, G.; ARUN, T.; SAYÝNSU, K.; ISIK, F. The role of cervical headgear and lower utility arch in the control of the vertical dimension. Am. J. Orthod. Dentofacial Orthop., St. Louis, v. 130, p. $492-501,2006$

29. URIAS, D.; MUSTAFA, F. I. A. Anchorage control in bioprogressive vs Straight-wire treatment. Angle Orthod., Appleton, v. 75, no. 6, p. 987-992, 2005

30. URIBE, F.: NANDA, R. Treatment of Class II, Division 2 malocclusion in adults: biomechanical considerations. J. Clin. Orthod., Boulder, v. 37, no. 11, p. 599-606, 2003.

31. YOKOYAMA, M. S. Comunicação pessoal. Presidente Prudente/SP, 1995.
Endereço para correspondência

Márcio Antonio de Figueiredo

Rua Capitão Nascimento Filho 131, Vergueiro

CEP: 18.030-123 - Sorocaba / SP

E-mail: marcioafigueiredo@uol.com.br 